\title{
A 3D ductile constitutive mixed-mode model of cohesive elements for the finite element analysis of adhesive joints
}

\section{Anyfantis, Konstantinos; Tsouvalis, Nicholas G.}

Published in:

Journal of Adhesion Science and Technology

Link to article, DOI:

$10.1080 / 01694243.2012 .735900$

Publication date:

2013

Link back to DTU Orbit

Citation $(A P A)$ :

Anyfantis, K., \& Tsouvalis, N. G. (2013). A 3D ductile constitutive mixed-mode model of cohesive elements for the finite element analysis of adhesive joints. Journal of Adhesion Science and Technology, 27(10), 1146-1178. https://doi.org/10.1080/01694243.2012.735900

\section{General rights}

Copyright and moral rights for the publications made accessible in the public portal are retained by the authors and/or other copyright owners and it is a condition of accessing publications that users recognise and abide by the legal requirements associated with these rights.

- Users may download and print one copy of any publication from the public portal for the purpose of private study or research.

- You may not further distribute the material or use it for any profit-making activity or commercial gain

- You may freely distribute the URL identifying the publication in the public portal 


\title{
A 3D ductile constitutive mixed-mode model of cohesive elements for the finite element analysis of adhesive joints
}

Konstantinos N. Anyfantis ${ }^{\mathrm{a}, 1}$ and Nicholas G. Tsouvalis ${ }^{\mathrm{b}}$

a) Department of Wind Energy, Technical University of Denmark, Lyngby, Denmark

b) Shipbuilding Technology Laboratory, School of Naval Architecture and Marine Engineering, National Technical University of Athens, Greece

\begin{abstract}
In this paper a new traction-separation law is developed that represents the constitutive relation of ductile adhesive materials in Mode I, II and III. The proposed traction-separation laws model the elastic, plastic and failure material response of a ductile adhesive layer. Initially, the independent-mode proposed laws (loading and fracture in Mode I, II and III) are mathematically described and then introduced in a developed formulation that simulates the interdependency of the mixed-mode coupled laws. Under mixed-mode conditions, damage initiation is predicted with the quadratic stress criterion and damage propagation with the linear energetic fracture criterion. For verification and validation purposes of the proposed laws and mixed-mode model, steel adherends have been adhesively bonded with a structural ductile adhesive material in order to fabricate a series of single and double strap adhesive joint configurations. The specimens have been tested under uniaxial quasi-static load and the respective force and displacement loading history have been recorded. Corresponding numerical and experimental results have been compared for each joint case, respectively. Additionally, the developed stress fields (peel, in-plane and out-of-plane shear) are presented as they evolve during the loading of both joint cases.
\end{abstract}

Keywords: Mixed-mode fracture, Ductile adhesives, Cohesive elements, Cohesive Zone Modelling, Finite Element Analysis.

\footnotetext{
${ }^{1}$ Corresponding author: Tel.: +45 4525 1382; E-mail: kanyf@dtu.dk
} 


\section{Introduction}

Many methods exist for bringing together similar or dissimilar structural materials, in terms of the joining technique utilized. Conventional mechanical joints, such as bolted, pinned or riveted are preferred due to their simplicity and the disassembly ability that they offer for joining metal or composite materials. However, when a mechanical joint is loaded, local damage is induced at the fastener holes due to stress concentrations. This fact leads to the structural degradation of a joint and jeopardizes the structural integrity of the assembly structure.

Alternately, adhesive bonding techniques offer many advantages for joining metal or composite materials and have been adopted by many industries instead of fastener joints [1]. Adhesive joints offer high strength-to-weight ratio and, when properly designed, up to three times higher strength under shear loading compared to fastener joints. Stress concentrations are reduced, since peel and shear stresses are being developed with a relatively uniform way over the adhesive bondline [1].

In the framework of analysis and design of adhesive joints, two geometric configurations are utilized in the literature for the study of the adhesive material and its cooperation with given adherends, that is a Single Lap Joint (SLJ) and a Double Strap Joint (DSJ) [2]. These types of joints are preferred because many closed-form solutions are available in the literature regarding the developed stress and deformation field in both the adhesive and adherend materials [3, 4].

Adhesive joints in practical applications are characterized by their complex geometry which cannot be treated with analytical tools. Instead, numerical solutions resulting from Finite Element Methods can be utilized. The latter provide predictions for the behavior of adhesive joints that incorporate inherent geometrical or material non-linearities of the adherends or/and the adhesive. Conventional Finite Element Analysis (FEA) of structural adhesive joints involves continuum finite elements for the representation of the adherends and the adhesive materials. This technique leads to accurate predictions of the deformation and stress field in the entire adhesive material domain. 
Under the framework of the continuum mechanics approach, the maximum values of stress, strain or strain energy, predicted by the FE analyses, are usually used in the failure criterion and are compared with the corresponding material allowable values. Initially, the maximum principal stresses were proposed for very brittle materials whose failure mode is at right angles to the direction of maximum principal stress. This criterion ignores all the other principal stresses, even though they are not nil. Establishing the failure modes in lap joints bonded with brittle adhesives, Adams et al. in [1] have extensively used this criterion to predict joint strength with success. However, because of the singularity of stresses at re-entrant corners of joints, the stresses depend on the mesh size used and how close to the singular points the stresses are taken.

Von Mises yield criterion has been used to study the strength of adhesive joints [5]. However, this criterion is more applicable to material yielding than strength. Since adhesive joints are mostly shear-type joints several researchers have used the maximum shear stress criterion to predict joint strength [6, 7]. da Silva et al. in [3,4] showed for single lap joints that this criterion is only valid for brittle adhesives and short overlaps. This approach ignores the normal stresses existing in lap joints and therefore it overestimates the joint strength.

When ductile adhesives are used, criteria based on stresses are not appropriate because joints can still endure large loads after adhesive yielding. For ductile adhesives, Adams and Harris in [8] used the maximum principal strain as failure criterion for predicting the joint strength. This criterion can also predict the failure mode. However, it is equally sensitive to the mesh size, as previously discussed for the maximum principal stress approach.

Plastic energy density has also been used as a failure criterion [9], being similar to the total strain energy criterion but it only takes the plastic part of the deformation into account. Zhao et al. in [10] applied a criterion whereby if the average plastic energy density over a certain distance within the single lap joint reached a critical value, then the joint was deemed to have failed. The 
specific energy is not so sensitive to the size of the integration zone, as it is 'averaged' over an area (2D analyses) or volume (3D analyses).

Stresses are being transferred from one adherend to the other through the adhesive layer and via the adhesive/adherend interface. Cracks are prone to develop at the bi-material interfaces of an adhesive joint when the adhesive strength is higher than the interfacial strength (adhesive failure). On the other hand, when the adhesive strength is lower than the interfacial strength, cracks develop within the adhesive material (cohesive failure). Thus, conventional FEA techniques cannot explicitly predict the load carrying capacity (strength) of an adhesive joint, since cracks and hence fracture mechanics are not involved.

This gap was initially bridged with the utilization of the Virtual Crack Closure Technique (VCCT) within the framework of Linear Elastic Fracture Mechanics [11, 12, 13, 14]. A physical crack is modeled either in the adhesive layer or in the bi-material adhesive/ adherend interface or in both of them and a given load case is applied on the adhesive joint. The internal nodal forces are calculated at the crack tip together with the relative displacements of the adjacent nodes, which are later utilized for the calculation of the energy release rate $G$ in each fracture mode, respectively. Crack propagation occurs if the energy release rate magnitude is greater than the experimentally measured fracture toughness $G_{\mathrm{c}}$ of the material system, in a respective fracture mode.

For ductile materials, a large amount of material yielding occurs and the crack may propagate stably before final failure. Thus, LEFM does not work anymore for such materials. The HRR (Hutchinson Rice Rosengreen) solution developed by Hutchinson in [15] and by Rice and Rosengren [16] has, however, been extensively used in ductile fracture. Another important parameter governing failure is the so-called crack tip opening displacement [17]. However, a strain singularity still exists for ductile materials, even though the stress singularity has disappeared. The fracture of adhesive joints inherently takes place under mixed mode because of the varying properties between different materials and the complex stress system. Failure criteria for mixed 
mode fracture can be developed in a way analogous to the classical failure criteria, although the fracture surface (or envelope) concept must be introduced. Various mathematical surface functions have been proposed to fit the experimental results, such as the 3D criterion [18].

A step forward has been made with the introduction of the well-known cohesive elements to the simulation of adhesive joints, under the framework of Cohesive Zone Modeling (CZM) techniques [19, 20, 21, 22, 23, 24, 25]. This methodology allows the study of the debonding initiation and propagation process, without considering the presence of initial flaws and leads to the calculation of the load carrying capacity of the considered adhesive joint [2]. The available techniques for damage modelling can be separated into local or continuum approaches. In the local approach, damage is confined to a zero volume line or a surface, allowing the simulation of an interfacial failure between the adhesive bond and the adherend or/and of a cohesive failure [21,22]. By the continuum approach, the damage is modelled over a finite region along an adhesive bond to simulate a cohesive fracture of the adhesive bond [23].

The constitutive relation of cohesive elements is described by cohesive laws, that relate the tractions $\sigma$ with the corresponding separations $\delta$ (relative displacements between the two planes of the cohesive elements) i.e. traction-separation or T-S laws, $\sigma-\delta$. In general, a cohesive law is described by two parts, a traction strengthening part and a traction softening part, either of which may be linear or non-linear. In CZM techniques, the two approaches that can be used regarding the cohesive law type are the intrinsic and the extrinsic approach [26]. In the intrinsic approach, the tractions, starting from the origin, have a hardening (rising) part that denotes an increasing resistance of the cohesive surface to separation. The slope of this part of the cohesive law controls the stiffness of the cohesive area modeled. At a given separation, the cohesive traction reaches a maximum value $\sigma_{\mathrm{c}}$, corresponding to the cohesive strength. After that point, the traction-separation curve follows a softening (decreasing) path associated with the failure process. Tractions are being reduced until $\delta$ reaches a critical value $\delta_{\mathrm{c}}$, from which point onwards tractions are set to zero, thus 
leading to the creation of a traction-free surface (i.e. a physical crack). The energy release rate is the key parameter in the formulation of a cohesive law, since the area under the traction-separation curve corresponds to the fracture toughness $G_{\mathrm{c}}$ of the adhesive joint system. This approach was first introduced within the context of finite element methods by Needleman [27], who used a polynomial form for the traction-separation law in the modeling of void nucleation associated with particle debonding. In order to couple the fracture modes, Needleman utilized a polynomial based potential that has a periodic shear dependence and is given in terms of opening (Mode I) and sliding (Mode II) separations. Hence, by differentiating the global potential with respect to the opening and sliding separations, the normal and shear tractions where obtained, respectively, in a complex function of the separations.

Prior to the utilization of the CZM techniques to the numerical analysis of adhesive joints, the technology of cohesive laws has matured with the simulation of delamination growth in Mode I [28] and Mode II [29] of fibrous layered composite materials.

On the other hand, the extrinsic approach relies on the modeling of the softening (decreasing) part of the cohesive law only. The area under the curve also corresponds to the fracture toughness $G_{\mathrm{c}}$ of the cohesive zone. However, a steep ascend (very high stiffness) is included in the cohesive law for numerical purposes and prior to the softening part, without affecting the total area $\left(G_{\mathrm{c}}\right)$ under the law. The most common extrinsic model which is embedded in most commercial finite element software, is a linear one used extensively in a variety of fracture simulations. The extrinsic model requires the introduction of a separate criterion for the initiation of the failure process, whereas in the intrinsic model a damage initiation criterion is inherently included.

In the framework of CZM techniques, several cohesive laws are available that can be categorized into the following groups, based on their shape: polynomial, piece-wise linear, exponential and rigid-linear [30]. A methodology which relies on intrinsic cohesive laws for the numerical prediction of the loading and fracture behavior of adhesive joints is based on the 
Embedded Process Zone (EPZ) approach, introduced by Thouless and his co-workers [31, 32, 33]. According to the EPZ, the adhesive layer works as the continuum which provides and transfers tractions between the adherends (CZM continuum approach). From the numerical point of view, the adhesive material is totally represented by interface or cohesive elements that can model the kinematics incorporated in the EPZ. The constitutive relations are given in terms of opening and shear traction-separation laws under pure Mode I [31] and pure Mode II [33] loading and fracture, respectively.

The EPZ approach has been also applied in finite element models to simulate mixed - mode loading and fracture [32, 34, 35, 36]. Yang and Thouless [32] used the EPZ approach for the numerical prediction of geometries that undergo extensive plastic deformation under mixed - mode loading e.g. T-peel and single-lap specimens. The authors utilized a failure criterion together with the introduction of a phase angle to relate the pure Mode I and Mode II trapezoidal T-S laws and thus to develop a mixed-mode EPZ model. On the other hand, Campilho and his co-workers [34, 35, 36, 37] developed a cohesive mixed-mode damage model to predict the behavior of ductile adhesives with a trapezoidal shape T-S law representing loading and fracture of each fracture mode, within the framework of Elastic Plastic Fracture Mechanics.

The trapezoidal model has been proven to be an effective T-S law that can adequately model the coupling between the behavior of the adhesive/adherend interface and the behavior of the adhesive itself, namely the adhesive failure and plasticity, respectively.

Additionally, Paulino and his co-workers have conducted significant research on CZM techniques by developing new cohesive laws and by studying the effectiveness of the most common ones that are used for simulating the behavior of adhesive joints under various types of loading and fracture conditions [38, 39, 40]. More specifically, in [39, 40] the authors have conducted a comparative numerical-experimental study, in order to show the influence of the shape of three intrinsic cohesive laws (triangular, trapezoidal and exponential) to the Mode I fracture of pre- 
cracked adhesively bonded Double Cantilever Beam specimens. One of the authors' major conclusions is that the triangular and trapezoidal laws yield promising results in the undamaged region of cracked adhesive joints since the pre-peak slope of the corresponding traction-separation laws can be controlled (intrinsic type).

This paper presents a new T-S law which describes the Mode I, II and III loading and fracture of a ductile adhesive material constrained between adherends that form a structural adhesive joint. The current work is an extension of the proposed T-S law developed by Anyfantis and Tsouvalis in [20] which accounts for Mode I and II in a 2-dimensional space. It is noteworthy that the proposed model cannot distinguish between the fracture type (cohesive or adhesive), since the entire adhesive layer is modelled by cohesive elements that do not provide stress variations through-the-adhesive thickness.

The proposed model is based on the embedded process zone and considers the elastic, plastic and fracture behavior of ductile adhesive materials in a 3-dimensional space. In the present study the proposed T-S law is referred as proposed EPZ law. Initially, the independent-mode proposed laws (loading and fracture in Mode I, II and III) are mathematically described and then introduced in a developed formulation that simulates the interdependency of the mixed-mode coupled laws. For the numerical validation of the proposed EPZ laws and the mixed-mode model, two typical joint geometries have been adopted, that is a Single Lap Joint (SLJ) and a Double Strap Joint (DSJ). The response of the specimens was experimentally measured and numerically predicted. Additionally, for reasons of comparison, numerical results obtained from the already known trapezoidal laws are presented.

\section{Proposed mixed-mode EPZ model}

In this section the mathematical description and the numerical formulation of the intrinsic proposed traction-separation law is presented, which addresses the loading and fracture behavior of 
a ductile adhesive material in either pure Mode I, II and III or in mixed-mode conditions. The development of a cohesive model includes first the definition of the traction-separation law shapes and corresponding parameters in pure mode loading and fracture, and then their incorporation into a mixed-mode model that accounts for their interdependency under mixed-mode conditions. The latter formulation utilizes damage and failure criteria for the prediction of damage initiation and propagation, respectively. The proposed traction-separation laws and mixed-mode model have been implemented in Abaqus 6.10 FE software user element subroutine (UEL) as the constitutive relation of 16 node user-programmed plane cohesive elements. The formulation of the latter is based on the work reported in [41].

\subsection{Pure mode EPZ laws}

In this description, the proposed cohesive law is referred as proposed EPZ law, since it is based on the embedded process zone approach, described in the introduction. The proposed EPZ laws are formulated so as to be utilized for the 3-dimensinal simulation of adhesive joints and thus all three loading and fracture modes are included (Mode I, II and III). Figure 1 presents a graphical representation of the shape and parameters of the proposed EPZ laws.

The $\sigma_{\mathrm{I}}$ tractions that are used to describe loading and fracture in the Mode I EPZ law, express the normal to the adhesive bondline stresses, known as peel or cleavage stresses, whereas $\sigma_{\text {II }}$ and $\sigma_{\text {III }}$ tractions describe the in-plane and out-of-plane shear stresses, respectively. The traction strengthening part of the proposed laws is defined by an exponential function, which aims at describing the elastoplastic behavior of a ductile adhesive layer. This part differentiates the proposed EPZ law from the trapezoidal law which describes this region with an elastic - perfectly plastic approach, i.e. tractions are maintained constant after the initial linear elastic region (first inflexion point) until they enter the softening part (second inflexion point). For the description of the traction softening part (damage propagation) a linear function is utilized, as also given in the 
trapezoidal law. The selection of this particular shape of the proposed EPZ laws has been done on the basis that these two functions are very good analytical fits of experimentally measured tractionseparation laws obtained from steel-to-steel adhesive joints, which will be shown later in this section. The reversibility of the laws (unloading paths) has been included in the following formulation, as shown in Figure 1 by the linear unloading paths, for both traction strengthening and softening parts (dotted lines).

The analytical function utilized for the description of the elastoplastic behavior of a ductile adhesive material including its reversibility is given by the following equation:

$$
\sigma_{i}\left(\delta_{i}\right)=\frac{\sigma_{\mathrm{c}, i}}{\delta_{i, \max }}\left[1-\exp \left(-\frac{\delta_{i, \max } k_{i}}{\sigma_{\mathrm{c}, i}}\right)\right] \delta_{i} \quad \text { for } \quad 0 \leq \delta_{i}<\delta_{0, i}
$$

where subscript $i$ equals to I, II or III. The magnitude $\sigma_{\mathrm{c}, i}$ represents the critical stress and the magnitude $\delta_{0, i}$ is its corresponding separation at damage initiation under pure mode loading and fracture conditions. Magnitude $\delta_{i, \max }$ is equal to the maximum separation calculated at a converged time step of the non-linear analysis procedure. Thus, during loading, both $\delta_{i}$ and $\delta_{i \text {,max }}$ magnitudes are equal and together increasing and tractions follow the exponential function. However, if at given time step the calculated $\delta_{i}$ is less than $\delta_{i \text {,max }}$, unloading is detected and hence $\delta_{i \text {,max }}$ remains constant and equal to the last value of $\delta_{i}$. As aforementioned, during unloading, tractions follow the linear paths to conclude to the origin (see Figure 1).

In order to avoid interpenetration between the, adjacent to the cohesive elements, continuum elements, a penalty contact algorithm has been included only in the formulation of Mode I EPZ law (see Figure 1). The contact algorithm is activated when $\delta_{i}$ becomes less than zero and hence tractions are described by:

$$
\sigma_{\mathrm{I}}\left(\delta_{\mathrm{I}}\right)=k_{\mathrm{p}} \delta_{\mathrm{I}} \quad \text { for } \quad \delta_{\mathrm{I}}<0
$$


where $k_{\mathrm{p}}$ is the penalty magnitude $\left(\approx 10^{5} \div 10^{6} \mathrm{MPa} / \mathrm{mm}\right.$, [28]). It is assumed that negative stresses do not induce damage but treated only as contact conditions. The initial slope of Equation (1) is equal only to magnitude $k_{i}$, which is called initial stiffness, as seen from the following equation.

$$
\left.\frac{\partial \sigma_{i}}{\partial \delta_{i}}\right|_{\delta_{i}=0}=k_{i}
$$

This characteristic of the current exponential form is advantageous with regards to the development of the mixed-mode loading and fracture model, which will be described in the following. The initial stiffness $k_{i}$ is directly defined for each mode by dividing the corresponding elastic constant of the adhesive material with the adhesive thickness [34, 35, 36, 37], $k_{\mathrm{I}}=E_{\mathrm{a}} / t_{\mathrm{a}}, k_{\mathrm{II}}$ $=G_{\mathrm{a}} / t_{\mathrm{a}}$ and $k_{\mathrm{III}}=k_{\mathrm{II}}$, where $E_{\mathrm{a}}$ and $G_{\mathrm{a}}$ is the Young and shear modulus of the adhesive, respectively. Mode II corresponds to in-plane shear stresses whereas Mode III corresponds to outof-plane shear stresses (scissoring deformation). For an isotropic adhesive material, as the one utilized herein, both shear Mode II $\sigma_{\text {II }}$ and Mode III $\sigma_{\text {III }}$ stresses are proportional to shear strains: $\sigma_{\text {II }}$ $=G \gamma_{\mathrm{II}}$ and $\sigma_{\mathrm{III}}=G \gamma_{\mathrm{III}}$ via the adhesive's shear modulus $G_{\mathrm{a}}$. Since, $K_{i}$ is defined as the ratio of the corresponding elastic constant to the adhesive thickness, this explicitly yields that $K_{\mathrm{II}}=K_{\mathrm{III}}$.

Magnitude $\delta_{0, i}$ can be directly defined or implicitly calculated, considering that the exponential form of Equation (1), on a theoretical basis, tends asymptotically to the horizontal asymptote $\sigma_{\mathrm{c}, i}$. Thus, the corresponding ordinate is selected equal to $(1-e) \sigma_{\mathrm{c}, i}$, where (1-e) is the tolerance and $e$ is the numerical error between the asymptote $\sigma_{\mathrm{c}, i}$ and the corresponding value utilized in the numerical analysis, as depicted in Figure 2.

Substituting the left hand side of Equation 1 with the term $(1-e) \sigma_{c, i}$ and solving with respect to $\delta_{0, i}$, the following relation is obtained:

$$
\delta_{0, i}=-\frac{\ln (e) \sigma_{c, i}}{k_{i}}
$$


As aforementioned, damage initiation and propagation is described by a linear traction softening function in the proposed EPZ laws. The term damage includes every type of degradation occurring within the adhesive layer, i.e. porosity nucleation, micro-cracking development etc. The linear softening function utilized in the formulation laws, from the critical traction point to the traction-free regime is given by Equation (5).

$$
\sigma_{i}\left(\delta_{i}\right)=-\frac{(1-e) \sigma_{\mathrm{c}, i}}{\delta_{\mathrm{c}, i}-\delta_{0, i}} \delta_{i}+\frac{(1-e) \sigma_{\mathrm{c}, i} \delta_{\mathrm{c}, i}}{\delta_{\mathrm{c}, i}-\delta_{0, i}} \quad \text { for } \quad \delta_{0, i} \leq \delta_{i}<\delta_{\mathrm{c}, i}
$$

where $\delta_{c, i}$ is the critical separation. In order to include reversibility (unloading) in the softening part, a control parameter of the damage extension $D$ has been introduced which varies within the range $[0,1]$

$$
D=1-\frac{\delta_{0, i}\left(\delta_{\mathrm{c}, i}-\delta_{i, \max }\right)}{\delta_{i, \max }\left(\delta_{\mathrm{c}, i}-\delta_{0, i}\right)}
$$

At this point Equation (5) can be rewritten in the following form, which includes both loading and unloading:

$$
\sigma_{i}\left(\delta_{i}\right)=(1-D)(1-e) \sigma_{\mathrm{c}, i} \frac{\delta_{i}}{\delta_{0, i}} \text { for } \quad \delta_{0, i} \leq \delta_{i}<\delta_{\mathrm{c}, i}
$$

Beyond the critical separation, the corresponding tractions are set to zero, hence leaving behind new traction-free surfaces (physical cracking).

$$
\sigma_{i}\left(\delta_{i}\right)=0 \quad \text { for } \quad \delta_{i} \geq \delta_{\mathrm{c}, i}
$$

The total energy consumed at the end of the proposed EPZ law is given by the definite integral (area) of its curve. 


$$
J_{i \mathrm{c}}=\int_{0}^{\delta_{\mathrm{c}, i}} \sigma_{i} d \delta_{i}=\frac{\sigma_{\mathrm{c}, i}}{k_{i}}\left[k_{i} \delta_{0, i}-\sigma_{\mathrm{c}, i}+\sigma_{\mathrm{c}, i} \exp \left(-\frac{\delta_{0, i} k_{i}}{\sigma_{\mathrm{c}, i}}\right)\right]+\frac{1}{2} \sigma_{\mathrm{c}, i}\left(\delta_{\mathrm{c}, i}-\delta_{0, i}\right)
$$

Figure 3 presents the analytical fitting of a typical experimental T-S law (obtained from DCB and ENF tests [42, 43]) with the proposed EPZ laws (equations (1) and (5)), for both pure Mode I and pure Mode II, respectively. Despite the fact that the experimental T-S laws have been obtained for different adhesive systems (LOCTITE Hysol 9460 for the DCB tests and DOW Betamate XW1044-3 for the ENF tests) the mechanical behavior of both adhesive materials is characterized as ductile. According to Figure 3, the traction increasing part has been fitted with great accuracy by Equation (1), yielding a coefficient of determination $\left(R^{2}\right)$ equal to 0.98 and 0.99 for the Mode I (Figure 3a) and Mode II (Figure 3b) case, respectively. Having calculated the analytical fittings of the experimental traction increase parts and thus having obtained the corresponding to the Mode I and Mode II $k_{i}, \sigma_{\mathrm{c}, i}$ and $\delta_{0, i}$ magnitudes ( $i=\mathrm{I}$ or II), $e$ parameters can be easily derived through Equation (4). Hence, a value equal to $0.08 \%$ and $0.1 \%$ has been calculated for $e$ parameter in Mode I and Mode II laws, respectively.

On the other hand, the experimentally measured traction softening part (damage propagation region) has a linear trend with a local non-linearity at the beginning of the descent in Mode I, whereas in Mode II a highly non-linear behavior is attained. However, it is impossible to formulate the coupling (interdependency) between a linear and a highly non-linear softening response within a numerical scheme, in order to yield a mixed-mode constitutive model. Additionally, several studies [20, 22, 31, 32, 33, 34, 35] state that a linear softening is adequate for modelling the physical phenomena occurring during damage propagation in the EPZ. For this purpose, within the present study, no efforts were made to utilize a non-linear softening function and thus a linear description (Equation (5)) has been adopted. 


\subsection{Coupling of the pure mode EPZ laws}

Having defined the proposed EPZ laws in pure mode loading and fracture (Mode I, II and III), the next step is to formulate their interdependency under the framework of a mixed-mode model. The proposed mixed-mode model is presented in Figure 4. Two cases are considered according to the sign of the normal tractions $\sigma_{\mathrm{I}}$, since positive tractions contribute to the loading and fracture and negative tractions denote contact in the adhesive bondline. Thus, one case considers the Mode I, II and III mixity (positive $\sigma_{\mathrm{I}}$ ) and the remaining one considers only Mode II and III mixity (negative $\sigma_{\mathrm{I}}$ ).

\subsubsection{Mode I, II and III mixed-mode model}

The guiding parameters for the formulation of the mixed-mode model are the mode mixity ratios:

$$
\beta_{\mathrm{II}}=\frac{\delta_{\mathrm{II}}}{\delta_{\mathrm{I}}} \quad \text { and } \quad \beta_{\mathrm{III}}=\frac{\delta_{\mathrm{III}}}{\delta_{\mathrm{I}}}
$$

and the resultant total separation $\delta_{\mathrm{m}}$

$$
\delta_{\mathrm{m}}=\sqrt{\delta_{\mathrm{I}}^{2}+\delta_{\mathrm{II}}^{2}+\delta_{\mathrm{III}}^{2}}
$$

The current formulation is based on Equation (10) and Equation (11) for the composition of the mixed-mode EPZ laws for given pure mode EPZ laws, under constant mode mixity ratios. The same basic equations combined with damage initiation and propagation criteria are utilized for the definition of the parameters that characterize the three decomposed mixed-mode EPZ laws calculated from the mixed-mode model.

Damage initiation under mixed-mode loading is predicted with the use of the quadratic stress criterion [34]: 


$$
\left(\frac{\sigma_{\mathrm{cm}, \mathrm{I}}}{\sigma_{\mathrm{c}, \mathrm{I}}}\right)^{2}+\left(\frac{\sigma_{\mathrm{cm}, \mathrm{II}}}{\sigma_{\mathrm{c}, \mathrm{II}}}\right)^{2}+\left(\frac{\sigma_{\mathrm{cm}, \mathrm{III}}}{\sigma_{\mathrm{c}, \mathrm{III}}}\right)^{2}=1
$$

where $\sigma_{\mathrm{cm}, \mathrm{I}}, \sigma_{\mathrm{cm}, \mathrm{II}}$ and $\sigma_{\mathrm{cm}, \mathrm{III}}$ are the critical stresses of the decomposed mixed-mode EPZ laws (see Figure 4). Solving Equation (4) with respect to $\sigma_{\mathrm{c}, i}$ and $\sigma_{\mathrm{cm}, i}$ (for $i=\mathrm{I}$, II and III) separately and substituting to Equation (12), the stress criterion is written as:

$$
\left(\frac{\delta_{0 \mathrm{~m}, \mathrm{I}}}{\delta_{0, \mathrm{I}}}\right)^{2}+\left(\frac{\delta_{0 \mathrm{~m}, \mathrm{II}}}{\delta_{0, \mathrm{II}}}\right)^{2}+\left(\frac{\delta_{0 \mathrm{~m}, \mathrm{II}}}{\delta_{0, \mathrm{II}}}\right)^{2}=1
$$

where $\delta_{0 \mathrm{~m}, \mathrm{I}}, \delta_{0 \mathrm{~m}, \mathrm{II}}$ and $\delta_{0 \mathrm{~m}, \mathrm{III}}$ are the obtained mixed-mode separations denoting the actual damage initiation point. Substituting Equation (10) and (11) into Equation (13), the resultant total separation $\delta_{0 \mathrm{~m}}$ is obtained:

$$
\delta_{0 \mathrm{~m}}=\sqrt{\frac{1+\beta_{\mathrm{II}}^{2}+\beta_{\mathrm{III}}^{2}}{\frac{1}{\delta_{0, \mathrm{I}}^{2}}+\frac{\beta_{\mathrm{II}}^{2}}{\delta_{0, \mathrm{II}}^{2}}+\frac{\beta_{\mathrm{III}}^{2}}{\delta_{0, \mathrm{III}}^{2}}}}
$$

Substituting Equation (10) and (11) into Equation (14) the decomposed separation in Mode I loading and fracture is obtained:

$$
\delta_{0 \mathrm{~m}, \mathrm{I}}=\frac{\delta_{0, \mathrm{~m}}}{\sqrt{1+\beta_{\mathrm{II}}^{2}+\beta_{\mathrm{III}}^{2}}}
$$

and in Mode II and III loading and fracture:

$$
\delta_{0 \mathrm{~m}, \mathrm{II}}=\beta_{\mathrm{II}} \delta_{0 \mathrm{~m}, \mathrm{I}} \text { and } \quad \delta_{0 \mathrm{~m}, \mathrm{II}}=\beta_{\mathrm{III}} \delta_{0 \mathrm{~m}, \mathrm{I}}
$$


Having calculated $\delta_{0 \mathrm{~m}, \mathrm{I}}, \delta_{0 \mathrm{~m}, \mathrm{II}}$ and $\delta_{0 \mathrm{~m}, \mathrm{III}}$ the decomposed critical stresses $\sigma_{\mathrm{cm}, i}$ may be calculated for each Mode $i$, by utilizing Equation (4).

$$
\sigma_{\mathrm{cm}, i}=-\frac{k_{i} \delta_{0 \mathrm{~m}, i}}{\ln (e)}
$$

The decomposed EPZ laws maintain their initial slope $k_{i}$ (and thus their initial linear elastic stiffness) from the respective pure mode loading and fracture laws, as shown in Figure 4. This fact proofs the advantage of the selected exponential form (Equation (3)), according to which the linear elastic response is modeled regardless the mode-mixity ratios.

The linear energetic fracture criterion has been selected for the prediction of damage propagation within the adhesive layer, which provides the needed coupling between the fracture energies in Mode I ( $\left.J_{\mathrm{I}}\right)$, Mode II ( $\left.J_{\text {II }}\right)$ and Mode III ( $\left.J_{\text {III }}\right)$, [34].

$$
\frac{J_{\text {I }}}{J_{\text {Ic }}}+\frac{J_{\text {II }}}{J_{\text {IIc }}}+\frac{J_{\text {I }}}{J_{\text {II }}}=1
$$

From the physical point of view, the satisfaction of the preceding criterion denotes the elimination of the tractions within the embedded process zone and thus new traction-free surfaces are being generated. Fracture energies $J_{i}$ are being calculated, as in Equation (9), through the definite integral of the decomposed mixed-mode EPZ laws:

$$
J_{i}=\int_{0}^{\delta_{\mathrm{cm}, i}} \sigma_{i} d \delta_{i}=\frac{\sigma_{\mathrm{cm}, i}}{k_{i}}\left[k_{i} \delta_{0 \mathrm{~m}, i}-\sigma_{\mathrm{cm}, i}+\sigma_{\mathrm{cm}, i} \exp \left(-\frac{\delta_{0 \mathrm{~m}, i} k_{i}}{\sigma_{\mathrm{cm}, i}}\right)\right]+\frac{1}{2} \sigma_{\mathrm{cm}, i}\left(\delta_{\mathrm{cm}, i}-\delta_{0 \mathrm{~m}, i}\right)
$$

Substituting Equation (9) and Equation (19) into Equation (18), an exact calculation of the decomposed critical separations $\delta_{\mathrm{cm}, \mathrm{I}}, \delta_{\mathrm{cm}, \mathrm{II}}$ and $\delta_{\mathrm{cm}, \mathrm{III}}$ is obtained, respectively: 


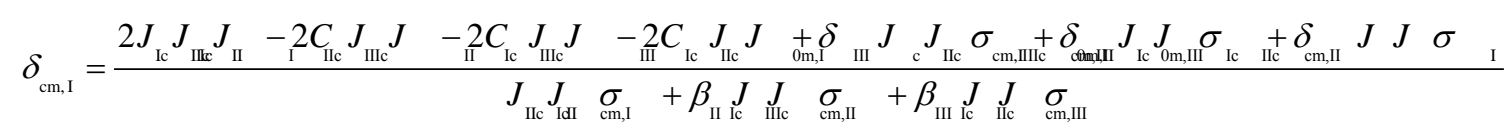

$\delta_{\mathrm{cm}, \mathrm{II}}=\beta_{\mathrm{II}} \delta_{\mathrm{cm}, \mathrm{I}}$

$\delta_{\mathrm{cm}, \mathrm{III}}=\beta_{\mathrm{IIII}} \delta_{\mathrm{cm}, \mathrm{I}}$

where $C_{i}$ ( $i=$ I, II and III) is the area under the decomposed EPZ laws that is given from the exponential function.

$$
C_{i}=\left(\frac{\sigma_{\mathrm{cm}, i}}{k_{i}}\right)\left[\left(\delta_{0 \mathrm{~m}, i} k_{i}\right)+\sigma_{\mathrm{cm}, i} \exp \left(-\frac{\delta_{0 \mathrm{~m}, i} k_{i}}{\sigma_{\mathrm{cm}, i}}\right)-\sigma_{\mathrm{cm}, i}\right]
$$

Magnitude $\delta_{\mathrm{cm}}$ is calculated through Equation (11).

$$
\delta_{\mathrm{cm}}=\sqrt{\delta_{\mathrm{cm}, \mathrm{I}}^{2}+\delta_{\mathrm{cm}, \mathrm{II}}^{2}+\delta_{\mathrm{cm}, \mathrm{III}}^{2}}
$$

Having calculated all necessary parameters involved in the mixed-mode EPZ laws, their computational implementation is provided. Loading and unloading is also considered in the mixedmode laws. The traction increasing part is given from the following equation, which is similar to Equation (1):

$$
\sigma_{\mathrm{m}, i}\left(\delta_{i}\right)=\frac{\sigma_{\mathrm{cm}, i}}{\delta_{i, \max }}\left[1-\exp \left(-\frac{\delta_{i, \max } k_{i}}{\sigma_{\mathrm{cm}, i}}\right)\right] \delta_{i} \quad \text { for } \quad 0 \leq \delta_{i}<\delta_{0 \mathrm{~m}, i}
$$

A damage parameter is also used that controls the extension of failure $D$ within range $[0,1]$ :

$$
D=1-\frac{\delta_{0 \mathrm{~m}}\left(\delta_{\mathrm{cm}}-\delta_{\mathrm{m}}\right)}{\delta_{\mathrm{m}}\left(\delta_{\mathrm{cm}}-\delta_{0 \mathrm{~m}}\right)}
$$


The softening part is given by the following function:

$$
\sigma_{\mathrm{m}, i}\left(\delta_{i}\right)=(1-D)(1-e) \sigma_{\mathrm{cm}, i} \frac{\delta_{i}}{\delta_{0 \mathrm{~m}, i}} \quad \text { for } \quad \delta_{0 \mathrm{~m}} \leq \delta_{\mathrm{m}}<\delta_{\mathrm{cm}}
$$

Lastly, tractions after the critical separations are being totally released:

$$
\sigma_{\mathrm{m}, i}\left(\delta_{i}\right)=0 \quad \text { for } \quad \delta_{\mathrm{m}} \geq \delta_{\mathrm{cm}}
$$

\subsubsection{Mode II and III mixed-mode model.}

In the case where tractions $\sigma_{\mathrm{I}}$ are negative and assuming that these negative tractions do not induce any damage but act only as contact stresses, coupling between only Mode II and III loading and fracture is present. The coupling of the two modes is given by one mode mixity ratio:

$$
\beta_{\mathrm{c}}=\frac{\delta_{\mathrm{II}}}{\delta_{\mathrm{III}}}
$$

and, consequently, the resultant total separation $\delta_{\mathrm{m}}$ is given by:

$$
\delta_{\mathrm{m}}=\sqrt{\delta_{\mathrm{II}}^{2}+\delta_{\mathrm{III}}^{2}}
$$

For the prediction of damage initiation, the quadratic stress criterion is being utilized:

$$
\left(\frac{\sigma_{\mathrm{cm}, \mathrm{II}}}{\sigma_{\mathrm{c}, \mathrm{II}}}\right)^{2}+\left(\frac{\sigma_{\mathrm{cm}, \mathrm{III}}}{\sigma_{\mathrm{c}, \mathrm{III}}}\right)^{2}=1
$$

Solving Equation (4) with respect to $\sigma_{\mathrm{c}, i}$ and $\sigma_{\mathrm{cm}, i}$ (for $i=$ II and III) separately and substituting to Equation (29), the stress criterion is written as: 


$$
\left(\frac{\delta_{0 \mathrm{~m}, \mathrm{II}}}{\delta_{0, \mathrm{II}}}\right)^{2}+\left(\frac{\delta_{0 \mathrm{~m}, \mathrm{II}}}{\delta_{0, \mathrm{II}}}\right)^{2}=1
$$

Substituting Equation (27) and Equation (28) into Equation (30) the resultant total separation $\delta_{0 \mathrm{~m}}$ is obtained:

$$
\delta_{0 \mathrm{~m}}=\sqrt{\frac{1+\beta_{\mathrm{c}}^{2}}{\frac{\beta_{\mathrm{c}}^{2}}{\delta_{0, \mathrm{II}}^{2}}+\frac{1}{\delta_{0, \mathrm{III}}^{2}}}}
$$

Separations $\delta_{0 \mathrm{~m}, \mathrm{II}}$ and $\delta_{0 \mathrm{~m}, \mathrm{III}}$ are calculated through Equations (27), (28) and (30):

$$
\delta_{0 \mathrm{~m}, \mathrm{II}}=\beta_{\mathrm{c}} \delta_{0 \mathrm{~m}, \mathrm{III}} \quad \text { and } \quad \delta_{0 \mathrm{~m}, \mathrm{II}}=\frac{\delta_{0, \mathrm{~m}}}{\sqrt{1+\beta_{\mathrm{c}}^{2}}}
$$

The decomposed critical stresses are calculated with the use of Equation (17) for $i=$ II or III. Damage propagation is predicted again with the use of the linear energetic criterion:

$$
\frac{J_{\text {II II }}}{J_{\text {IIc Ic }}}+\frac{J_{\text {II }}}{J_{\text {II }}}=1
$$

By substituting Equation (9) and Equation (19) into Equation (33), an exact expression is derived for $\delta_{\mathrm{cm}, \mathrm{II}}$ and $\delta_{\mathrm{cm}, \mathrm{III}}$, respectively:

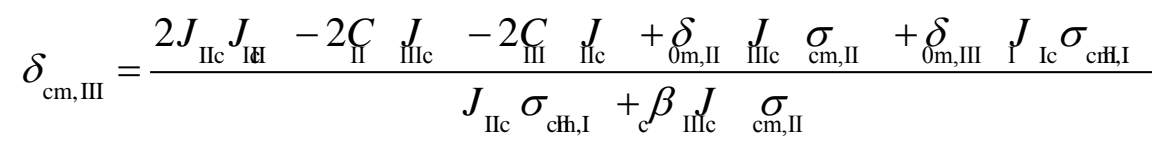

$$
\begin{aligned}
& \delta_{\mathrm{cm}, \mathrm{II}}=\beta_{\mathrm{c}} \delta_{\mathrm{cm}, \mathrm{III}}
\end{aligned}
$$

where $C_{i}(i=$ II and III $)$ is given by Equation (21). 


\section{Experimental work}

Two typical metal-to-metal adhesive joint configurations have been taken under consideration for the numerical validation of the proposed EPZ mixed-mode model, that is a Single Lap Joint (SLJ) and a Double Strap Joint (DSJ) geometry. In both joint cases, the adhesive material is loaded under mixed-mode conditions (Mode I and II dominant fracture modes) [2].

Figure 5 presents the geometry and the nominal dimensions of the SLJ and DSJ specimens considered for experimental evaluation. The actual width of the SLJ and DSJ specimens is $28.5 \mathrm{~mm}$ and $23.5 \mathrm{~mm}$, respectively. Typical mild (normal marine grade) steel has been utilized for all metal adherends (strap and inner adherends). The structural adhesive system utilized for the fabrication of the adhesive joints is Araldite 2015, a relatively stiff two-component epoxy adhesive provided by Huntsman Container Corporation Ltd. The nominal thickness of the adhesive layer was $0.5 \mathrm{~mm}$ and spacers had been placed in-between the adherends during manufacturing to keep this value constant for all specimens. Prior to the fabrication of the DSJs, the two inner $10 \mathrm{~mm}$ adherends were placed in contact, without any adhesive in-between them and thus avoiding the creation of a butt joint.

Three specimens from each joint configuration (six in total) were tested under a tensile loading using a MTS hydraulic testing machine at room temperature under displacement control with a rate of $0.1 \mathrm{~mm} / \mathrm{min}$. The experimental setup is shown in Figure 6 for each joint case. The experimental measurements are presented in the next section, together with the numerical ones.

\section{Numerical analysis of the Single Lap and Double Strap joints.}

The numerical simulation of the experimental tests of the SLJ and the DSJ has been conducted in Abaqus 6.10 commercial finite element software. The main aim is to validate the proposed mixed-mode EPZ model and provide predictions of the loading and failure behavior of the adhesive joints considered. 


\subsection{Finite element modeling}

Figure 7 and Figure 8 present the finite element models constructed for the simulation of the SLJ and DSJ joints, respectively. For the case of the SLJ geometry, loading and boundary conditions have been applied on the areas of the tabs that are constrained in the grips of the testing machine, as shown in Figure 7. As far as the DSJ case is concerned, the 1/4 part has been modeled due to its geometrical, loading and boundary conditions symmetry, and the corresponding constrains have been applied to its boundary domain, as depicted in Figure 8. Quadratic 20-node brick elements (C3D20) available in the Abaqus element library have been utilized for the metal adherends in both cases. The whole adhesive layer is represented by cohesive elements (placed between adjacent continuum elements in the overlap areas) and the proposed EPZ mixed-mode model has been utilized for the description of their constitutive relation. Cohesive elements are not so sensitive as far as their mesh density is concerned [20, 21, 22]. However, a mesh sensitivity analysis has been conducted by taking under consideration three different cohesive element dimensions, i.e. $(0.2 \times 0.2) \mathrm{mm}^{2},(0.5 \times 0.5) \mathrm{mm}^{2}$ and $(1 \times 1) \mathrm{mm}^{2}$. Their effect to the joints' strength was less than 3\%. The results provided herein are based on models which have cohesive elements with constant dimensions equal to $(0.5 \times 0.5) \mathrm{mm}^{2}$ in the entire overlap area. This was decided since this value has yield better stress resolutions on the adhesive domain rather than utilizing $(1 \times 1) \mathrm{mm}^{2}$. On the other hand the models with $(0.2 \times 0.2) \mathrm{mm}^{2}$ cohesive element dimensions are CPU cost ineffective and at the same time yield identical stress results as the $(0.5 \mathrm{x}$ 0.5) $\mathrm{mm}^{2}$ cohesive elements do. Thus, the SLJ model contains 84000 continuum elements and 2500 cohesive elements, whereas the DSJ model contains 60900 continuum elements and 5000 cohesive elements.

For the numerical integration of the stiffness matrix and the internal force vector of the 3D cohesive elments, a 3 x 3 Gaussian quadrature rule has been used. The Newton-Raphson method 
has been utilized for the solution of the displacement control non-linear problem augmented by the line search algorithm.

The implementation of the proposed mixed-mode EPZ model, within the framework of the cohesive finite element formulation, requires the definition of the parameters of the proposed pure mode EPZ laws (Mode I, II and III loading and fracture), that characterize the structural ductile adhesive material modeled (HUNTSMAN Araldite 2015). The accurate definition of a numerical cohesive law is based on experimental measurements obtained from an adhesively bonded Double Cantilever Beam (DCB) and End Notch Flexure (ENF) test, for the derivation of the corresponding parameters in Mode I and II loading and fracture, respectively. Given the fact that such experiments are not available in the current work, corresponding information has been taken form the literature ([37], [42]). The parameters utilized for the definition of the proposed pure mode EPZ laws are listed in Table 1.

For the calculation of the initial elastic stiffness $k_{\mathrm{I}}, k_{\mathrm{II}}$ and $k_{\mathrm{III}}$ in Mode I, II and III loading, $E_{\mathrm{a}}$ was taken equal to $1850 \mathrm{MPa}, G_{\mathrm{a}}$ equal to $711.5 \mathrm{MPa}$ and $t_{\mathrm{a}}$ equal to $0.5 \mathrm{~mm}$. The parameters used for the Mode II law are also used for the Mode III law. The critical stresses $\sigma_{\mathrm{c}, \mathrm{I}}$ and $\sigma_{\mathrm{c}, \mathrm{II}}$ have been taken equal to the tensile and shear strength of the adhesive, respectively, as these are provided by its manufacturer [44]. Fracture toughness $J_{\text {Ic }}$ has been also taken from the manufacturer's data sheet, calculated from steel-to-steel experiments, whereas fracture toughness $J_{\text {IIc }}$ has been taken from reference [37]. Since, crack propagation is an energy based prediction, then magnitude $J_{\text {ic }}$ should correspond to the steady-state fracture toughness level. Nevertheless, the adhesive material used herein, Araldite 2015, does not have a typical R-curve for Mode I and Mode II, meaning that the initial and steady-state fracture toughness levels cannot be distinguished, as concluded in [37, 45].

Additionally, parameters $\delta_{0, \mathrm{I}}, \delta_{0, \mathrm{II}}$ and $\delta_{0, \mathrm{III}}\left(\delta_{0, \mathrm{II}}=\delta_{0, \mathrm{III}}\right)$ are needed for the complete definition of the proposed EPZ laws. Since, experimental information about these specific values is 
not provided, Equation (4) has been utilized for their derivation. As described in section 2.1, these parameters are defined through the error $e$, which is a numerical parameter without a physical interpretation. Thus, their values are calculated through a best fit analysis between the corresponding numerical and experimental results, which has led to a common value of $0.1 \%$ utilized for the prediction of both joint geometries. It is noteworthy to mention that the experimental cohesive laws that describe Mode I [43] and Mode II [44] loading and failure, even though obtained from different ductile adhesive systems (LOCTITE Hysol 9460 for the DCB tests and DOW Betamate XW1044-3 for the ENF tests) than the one utilized in this work (Huntsman Ltd. Araldite 2015), yield an error $e$ equal to $0.08 \%$ and $0.1 \%$, respectively, as derived through a best fit analysis (see Figure 3). Despite the fact of the different adhesive systems used, the value of $e$ obtained from the best fit analysis of both SLJ and DSJ models is equal to the corresponding one calculated from the best fit analysis of the Mode II experimental law (0.1\%) and close enough to the one obtained from the Mode I law (0.08\%). This is good evidence that the error value obtained from the best fit analysis of the SLJ and DSJ models is not arbitrary. A sensitivity analysis regarding the effect of the error $e$ value to the finite element predictions is given later on this work.

For reasons of comparison, the trapezoidal model described in reference [36] has been also programmed and the corresponding numerical results have been compared with the ones obtained from the proposed EPZ mixed-mode model. The trapezoidal laws have an additional parameter $\delta_{2, i}$ ( $i=$ I, II and III) that needs to be defined, which corresponds to the second inflexion point. These parameters have been taken equal to the respective $\delta_{0, i}(i=\mathrm{I}$, II and III) parameters calculated through the error $e$, since, from the physical point of view, both refer to the damage initiation point. Thus, $\delta_{2, \mathrm{I}}$ and $\delta_{2, \mathrm{II}}\left(\delta_{2, \mathrm{III}}=\delta_{2, \mathrm{II}}\right)$ have been taken equal to $0.0691 \mathrm{~mm}$ and $0.898 \mathrm{~mm}$, respectively, for both joint models. 


\subsection{Results}

The applied force (reaction force resulting from the prescribed displacement) on the SLJ and DSJ models is being transferred from one adherend to the other through the adhesive layer, which is modeled with cohesive elements and its material response is described by the proposed mixed-mode EPZ model. The calculated separations $\left(\delta_{\mathrm{I}}, \delta_{\mathrm{II}}\right.$ and $\left.\delta_{\mathrm{III}}\right)$ at a given Gaussian point of a cohesive element laying at the adhesive bondline determine the stress state (elasticity, plasticity or damage) of the current material point of the adhesive layer, as described in section 2. Within the linear elastic region, where the developed tractions are analogous to the separations through the $k_{\mathrm{I}}, k_{\mathrm{II}}$ and $k_{\mathrm{III}}$ stiffness constants, the resulting von Mises equivalent stresses developed at the steel adherends of the SLJ and DSJ configurations are presented in Figure 9.

The global response of the SLJ and DSJ configurations, as experimentally registered and numerically evaluated, is presented in Figure 10. The experimental measurements from all three specimens tested for each case are plotted. Table 2 and Table 3 list the experimental and numerical maximum attained force and displacement levels for the SLJ and DSJ case, respectively. As regards to the experimentally obtained global responses of both cases (see Figure 10), they can be separated in three regions. The first region is described by a linear behavior, followed by gradually increasing non-linearities up to the load carrying capacity level of each joint, which bounds the second region of the curves. The third region is described by a softening behavior, which denotes the inability of each joint to carry further load. In this region failure mechanisms are developing in the adhesive/adherend system, i.e. void nucleation in the adhesive, debonding at the adhesive/adherend interface, micro-cracking, etc. The proposed model is formulated to predict the load bearing capacity of an adhesive joint, which is a result of the adhesive's ductility and both damage initiation and propagation process. For the joints utilized in this work, where the adherends are stiff (steel material and thick), the entire adhesive layer enters plasticity prior to damage propagation, as will 
be shown in section 4.4 through the presentation of corresponding stress variations. The joints reach their ultimate capacity because the entire adhesive layer has entered plasticity.

Figure 10 includes also the numerical predictions obtained from the trapezoidal and the proposed mixed-mode model. The proposed EPZ laws and mixed-mode model predict with great accuracy the initial linear and the following non-linear region of the global responses of both joints. It is concluded that this behavior depends strongly on the adhesive material elastoplastic response, described by the exponential behavior of the EPZ laws. On the other hand, the corresponding FEA results obtained with the trapezoidal laws capture the initial linear region but fail to capture the experimental non-linear region, in both cases. However, both models predict accurately the strength (load carrying capacity) of each joint, having a percentage difference from the average experimental value equal to $2.96 \%$ for the proposed and $4.24 \%$ for the trapezoidal mixed-mode model, for the SLJ case. For the DSJ case, a corresponding percentage difference of $1.52 \%$ and $1.99 \%$ has been calculated.

The predicted softening behavior (region after the joints' strength) by both the proposed and the trapezoidal mixed-mode models is not accurate compared to the corresponding experimental behavior, for both joint geometries. The experimental softening is characterized as sudden and dynamic. This leads to the conclusion that crack initiation and propagation (debonding process) in the adhesive layer is dynamic. As shown in section 4.4, at the maximum attained force of both joint configurations, shear stresses have become plastic in almost the entire domain of the adhesive layer. After that point, shear stresses reduce in magnitude according to the proposed mixed-mode model and the linear softening function, in a stable and uniform manner. This inconsistency with the experimental recordings is attributed to the fact that the numerical formulation of the current FE analysis of the joints does not account for inertia and dynamic effects (time dependency of equations of motion), but only the steady-state evolution of the phenomena is modeled. Thus, accurate predictions of the dynamic fracture and debonding (softening region) cannot be established. 
However, for the current adhesive joints considered and within a general analysis and design framework, the joint strength and its loading region are the issues of major interest.

As far as the maximum attained displacement, both the proposed and the trapezoidal EPZ model underestimate and overestimate the corresponding experimental values in the SLJ and DSJ predictions, respectively, as shown in Figure 10 and listed in Table 2 and Table 3. This is of insignificant importance, when designing an adhesive joint towards its strength (load capacity).

The aforementioned predictions are obtained with a common value of the error parameter $e$ equal to $0.1 \%$ for both the SLJ and the DSJ models. The corresponding $\delta_{0, i}$ ( $i=$ I, II and III) parameters of the proposed EPZ laws are set equal to the $\delta_{2, i}(i=\mathrm{I}$, II and III) parameters of the trapezoidal laws, for reasons of comparison. The following section deals with a sensitivity analysis of the effect of error $e$ on the corresponding FEA results, in order to show the effectiveness of the proposed EPZ laws and mixed-mode model.

\subsection{Sensitivity analysis of error $e$}

As aforementioned, the physical parameters of the proposed EPZ pure mode laws utilized in the numerical predictions of the SLJ and DSJ are listed in Table 1 . However, the parameters $\delta_{0, i}(\mathrm{i}=$ I, II and III) are unknown since corresponding experimental values are not available and hence they are calculated through Equation 4 by introducing the error parameter $e$. According to Figure 3 and the corresponding description given in section 2.1 and section 4.1, an error parameter $e$ equal to $0.1 \%$ has been utilized. However, for reasons of completeness, a parametric finite element analysis is reported herein regarding the sensitivity of error parameter $e$. The corresponding results are presented in Figure 11 in terms of the global response of the SLJ and DSJ models. Given the parameters of Table 1 , three values have been considered regarding error $e$ for each geometrical configuration:

- $e=1 \%$ 
- $e=0.1 \%$

- $e=0.01 \%$

It is noteworthy that in all three cases considered the values of the fracture toughness $J_{\mathrm{c} i}(i=$ I, II and III) utilized are common. According to Figure 11, it can be concluded that, for both cases, there is a small effect of error $e$ on the maximum attained load (strength) but a higher effect on its corresponding displacement. Thus, a value of error $e$ less than $1 \%$ yields accurate strength predictions and conservative predictions regarding the corresponding displacement. This conclusion is in agreement with the corresponding one reported in reference [20], where the simulation of the adopted adhesive joints is based on a 2-dimensional space and thus only Mode I and II loading and fracture are present. When designing an adhesive joint with respect to its strength, the proposed EPZ model yields very promising results, since an error $e$ value ranging from 0.01 to $1 \%$ does not affect the linear and the non-linear load path (see Figure 11) up to the strength limit. This is significant during the analysis and design of a ductile adhesive joint, because yield initiation (point where the non-linear region initiates in the $P$ - $u$ plots) is usually taken as the load allowable limit.

\subsection{Stress distributions on the bond area}

This section aims at providing the calculated stress fields on the adhesive area domains of the SLJ and DSL models, as calculated with the proposed EPZ mixed-mode model. The Embedded Process Zone approach, under which the proposed model was formulated, does not distinguish between the separate fracture modes. This is because the entire adhesive layer is modelled with cohesive elements that do not provide a through-the-adhesive thickness description of the displacement and stress field. Thus, the calculated stresses are interpreted as the average stresses developing in the middle line of the adhesive thickness.

Peel stress $\sigma_{z}$, in-plane shear $\tau_{x z}$ and out-of-plane shear $\tau_{y z}$ stresses correspond to the Mode I, II and III loading and failure modes, respectively. For the presentation of the calculated stress fields, 
2-dimensional contour graphs have been utilized with normalized axes, as schematically shown in Figure 12 for the SLJ and the DSJ configurations. It is reminded that, since $1 / 4$ of the DSJ configuration has been modeled, corresponding results are presented on half of the DSJ bond area. Figures 13 and 14 present the $\sigma_{z}$ and $\tau_{x z}$ stress variations at three levels throughout the non-linear loading history of the SLJ model; at $0.01 \mathrm{~mm}$ (very early, linear phase), at $0.1 \mathrm{~mm}$ (when response starts to deviate from linearity) and at $0.2 \mathrm{~mm}$ (near the maximum load). Figure 15 presents the outof-plane shear stress $\tau_{y z}$ variation only for the last level, since these stress values are very small.

At a first glance, the peel and in-plane shear stresses are symmetrical both with respect to $x$ direction (at $y / w=0.5$ ) and with respect to $y$ direction (at $x / L=0.5$ ). On the other hand, out-of-plane shear stresses are anti-symmetrical, a behavior which is reasonable since the SLJ geometry is antisymmetric by nature. The linear elastic $\sigma_{z}$ and $\tau_{x z}$ stress variations (Figures 13a and 14a) present a peak at the middle of the two opposite x-edges $(x / L=0$ and 1$)$, reducing in a non-linear manner as $x / L$ tends to 0.5 . More specifically, in this early stage peel stresses are negative in most of the adhesive area, a fact that denotes contact conditions, whereas in-plane shear stresses are very small. At the next evaluation point $(u=0.1 \mathrm{~mm}$, Figures $13 \mathrm{~b}$ and $14 \mathrm{~b})$, negative peel stresses cover a slightly smaller area than before, whereas in-plane shear stresses have redistributed and peak at the four corners of the adhesive area. At the maximum joint strength point $(u=0.2 \mathrm{~mm}$, Figures 13c and 14c), lower value peel stresses are generally obtained, with the negative stresses denoting contact developing in a quite smaller area than before. The corresponding in-plane shear stresses attain their maximum values (18.5 MPa) in most of the adhesive area, becoming lower near the edges in $x$-direction $(x / L=0$ and 1$)$. This maximum value is equal to the shear strength of the adhesive $\sigma_{\mathrm{c}, \mathrm{II}}$ (see Table 1), a fact that shows that the SLJ configuration is shear dominated.

The out-of-plane shear stresses $\tau_{y z}$, presented in Figure 15 , remain at very low levels $(0.75$ $\mathrm{MPa}$ ) and thus can be characterized as elastic during the whole SLJ's loading history. In fact $\tau_{y z}$ stresses do not contribute significantly to the loading and failure of the adhesive layer. 
Figure 16 presents the contribution of the $\sigma_{z}, \tau_{x z}$ and $\tau_{y z}$ stresses to the satisfaction of the quadratic stress criterion (see Equation 12 and Equation 29), utilized for modelling damage initiation. Each sequential term of the criterion corresponds to subplot (a), (b) and (c) of Figure 16, respectively, which all refer to the maximum attained load of the SLJ model. The denominator of all terms is equal to $\sigma_{\mathrm{c}, i}(1-e)$, since the actual utilized value of the critical stress is multiplied by the tolerance (1-e), as described in the formulation part of the mixed-mode model. By adding all terms (maximum value of each subplot's colour map), one can easily see that the criterion is satisfied in the entire adhesive domain. Mostly responsible are the shear stresses.

Same as before, Figures 17 and 18 present the peel, $\sigma_{z}$, and the in-plane shear, $\tau_{x z}$, stress variations at three levels throughout the non-linear loading history of the DSJ model; at $0.01 \mathrm{~mm}$ (very early, linear phase), at $0.07 \mathrm{~mm}$ (when response starts to deviate from linearity) and at 0.11 mm (near the maximum load). Figure 19 presents the out-of-plane shear, $\tau_{y z}$, stress variation only for the last level, since these stress values are very small. As a general observation, the peel and inplane shear stresses are symmetrical both with respect to $x$ direction (at $y / w=1$ ) and with respect to $y$ direction (at $x / L=0.5$ ), reminding that only half of the bond area is shown in these figures. The out-of-plane shear stresses however, are symmetrical with respect to $x$ direction $($ at $y / w=1)$ and anti-symmetrical with respect to $y$ direction (at $x / L=0.5$ ). The linear elastic $\sigma_{z}$ stresses (Figure 17a) peak at the middle of the adhesive's free edge $(x / L=0, y / w=0.5)$ and are being reduced in a nonlinear manner as $x / L$ tends to 0.2 . These stresses are negative in most of the adhesive area, a fact that denotes contact conditions. Within the area between $x / L=0.51$ and $x / L=0.76$, positive peel stresses develop, that remain in low levels compared to the maximum ones. The in-plane elastic shear stresses $\tau_{x z}$ (Figure 18a) develop in the entire bond area and peak at the middle of the joint (at $x / L=1)$

At the second evaluation point $(u=0.07 \mathrm{~mm}$ ), positive peel stresses (Figure 17b) develop in a larger area near the adhesive edge (from $x / L=0$ to 0.33 ) when compared to the corresponding 
stress field in Figure 17a. Also, the positive peel stress area between $x / L=0.51$ and $x / L=0.76$ vanishes. The peak values of the in-plane shear stresses at that point (Figure 17b) are again constrained at the middle of the joint (at $x / L=1$ ) and are being reduced towards position $x / L=0.5$.

At the maximum joint strength point ( $u=0.11 \mathrm{~mm}$, Figures 17c) peel stresses maintain their peak values at $x / L=0$ and develop in an extended area up to $x / L=0.4$. The peak stresses at $x / L=0$ are equal to 8.6 MPa, small compared to the tensile strength of the adhesive $\sigma_{\mathrm{c}, \mathrm{I}}$, which is equal to 30 MPa (see Table 1). The in-plane shear stresses $\tau_{x z}$ redistribute in a way that are reduced in the vicinity of $x / L=0$ and $x / L=1$ and maximize in the internal bond area (from $x / L=0.15$ and $x / L=$ 0.91). The maximum $\tau_{x z}$ values are equal to $18.31 \mathrm{MPa}$, a value close enough to the shear strength of the adhesive $\sigma_{\mathrm{c}, \mathrm{II}}(18.5 \mathrm{MPa})$. According to this last note, DSJ geometry can be characterized as a shear dominated joint type. The out-of-plane shear stresses $\tau_{y z}$, presented in Figure 19, remain at very low levels (0.99 MPa) and thus can be characterized as elastic during the whole DSJ's loading history. As was the case for the SLJ configuration too, stresses $\tau_{y z}$ do not significantly contribute to the loading and failure of the adhesive layer.

Figure 20 presents the contribution of the $\sigma_{z}, \tau_{x z}$ and $\tau_{y z}$ stresses to the satisfaction of the quadratic stress criterion at the maximum attained load of the DSJ model. Again, by adding all terms (maximum value of each subplot's colour map), one can easily see that the criterion is satisfied in the entire adhesive domain, due to shear stresses.

\section{Conclusions}

This work presents a novel traction-separation law that describes the behavior of a ductile adhesive material constrained between two continua, that is its elastic, plastic and failure behavior. The proposed EPZ laws aim at describing the embedded process zone (EPZ) formed within the adhesive bond area during the loading and failure of a structural adhesive joint. Therefore, its 
formulation is based on the Mode I, Mode II and Mode III loading and fracture and their interdependency that accounts for mixed-mode conditions. Initially the mathematical description of the pure mode laws is presented, followed by their incorporation in a developed mixed-mode model, which is based on damage and fracture criteria. The main difference of the proposed laws compared to the already known in the literature trapezoidal laws, is the shape of the stress strengthening part until failure initiation, which in our case is an exponential function instead of the bi-linear behavior included in the trapezoidal laws. For validation and verification reasons, a series of single lap and double strap joint configurations have been fabricated and tested and the corresponding finite element models have been constructed in a 3-dimensional space, for the prediction of their response. The proposed EPZ mixed-mode model has been utilized as the constitutive relation of the cohesive elements embedded in the adhesive area (interphase between adherends).

The trapezoidal law predicts accurately the linear elastic region and strength but fails to capture the nonlinear elastoplastic region of the tested joints. More specifically, the trapezoidal law predicts higher loads for a given value of applied displacement when compared to the corresponding results obtained from the proposed law and the experimental measurements, at least for the cases studied in this work where thick steel adherends and a ductile adhesive material have been utilized. This difference increases for values of load approaching the strength of the joints. This is a major conclusion, since, when designing a structural part that includes an adhesive joint, the proposed laws predict the global response and the stress distributions of the joint with higher accuracy than the trapezoidal law at this part of the joint response. Additionally, the proposed EPZ model predicts with great accuracy the experimentally measured average strengths of both joint cases, as occurs also with the trapezoidal model.

Four parameters are needed for defining each law in pure Mode $i$ ( $i=$ I, II and III). Specifically, the initial stiffness $\left(k_{i}\right)$, the critical stress $\left(\sigma_{\mathrm{c}, i}\right)$, its corresponding separation $\left(\delta_{0, i}\right)$ and the critical separation $\left(\delta_{\mathrm{c}, i}\right)$ or the fracture toughness $\left(J_{\text {ic }}\right)$. The critical stress, its corresponding 
separation and the fracture toughness are obtained from experimental cohesive laws, whereas the initial stiffness can be calculated easily by considering the elastic properties of the adhesive material given by the manufacturer. However, a numerical parameter, namely error $e$, has been defined that leads to the indirect calculation of the physical parameter $\delta_{0, i}$ through an analytic formula. Since, experimental cohesive laws were not available in our case, a best fit analysis on both joint configurations has yielded a common error $e$ value, which was further utilized for the prediction of the behavior of both joints considered.

The effect of this parameter to the FE results has been investigated through a sensitivity analysis, which has led to the conclusion that accurate predictions of the strength and conservative predictions of the corresponding displacement at failure are obtained, when considering a value of error $e$ equal to $1 \%$ or less. Thus, it can be concluded that the proposed EPZ laws can be referred to as two-parameter laws when designing towards the strength of an adhesive joint with a ductile adhesive material. However, when designing towards maximum attained displacement, the proposed laws are three-parameter laws.

The constitutive model presented here provides an alternative capability for the simulation and design of structures with bonded components which involve a ductile adhesive material. The validity of the proposed law can be further investigated for different adhesive joints and under different loading conditions that would lead the adhesive layer to stresses with a higher modemixity, including also the effect of Mode III loading and fracture. 


\section{References}

1. R.D. Adams, J. Comyn and W.C. Wake. Structural adhesive joints in engineering. Chapman \& Hall, London (1997).

2. N.G. Tsouvalis and K.N. Anyfantis. Applied Mechanics and Materials 24-25, 189 (2010).

3. L.F.M. da Silva, P.J.C. das Neves, R.D. Adams and J.K. Spelt. International Journal of Adhesion and Adhesives 29, 319 (2009).

4. L.F.M. da Silva, P.J.C. das Neves, R.D. Adams, A. Wang and J.K. Spelt. International Journal of Adhesion and Adhesives 29, 331 (2009).

5. K. Ikegami, T. Takeshita, K. Matsuo, T. Sugibayashi. International Journal of Adhesion and Adhesives 10, 385-400 (1990).

6. S.J. John, A.I. Kinloch, F.L. Matthews. Measuring and predicting the durability of bonded fibre/ epoxy composite joints. Composites 22, 121-127 (1991).

7. S.J. Lee, D.G. Lee. Journal of Adhesion 40: 1-14 (1992).

8. R.D. Adams, J.A. Harris. International Journal of Adhesion and Adhesives 4: 65- 78 (1984).

9. R.D. Adams, J.A. Harris. International Journal of Adhesion and Adhesives 7: 69-80 (1987).

10. X. Zhao, R.D. Adams, L.F.M. da Silva. Journal of Adhesion Science and Technology 25: 837856 (2011).

11. Y. Zhang, P.A. Vassilopoulos and T. Keller. Engineering Fracture Mechanics 77, 128 (2010).

12. E.F. Rybicki and M.F. Kanninen. Engineering Fracture Mechanics 9, 931 (1977).

13. K. Badarinarayana, B. Dattaguru, T.S. Ramamurthy and K. Vijayakumar. Engineering Fracture Mechanics 48, 167 (1994).

14. K.L. Singh, B. Dattaguru and T.S. Ramamurthy. Mechanics of Advanced Materials Structures 13, 303 (2006).

15. J.W. Hutchinson. Journal of the Mechanics and Physics of Solids 16: 13-31 (1968). 
16. J.R. Rice, G.F. Rosengren. Journal of the Mechanics and Physics of Solids 16: 1-12 (1968).

17. D.S. Dugdale. Journal of the Mechanics and Physics of Solids 8: 100-104 (1960).

18. D.A. Dillard, H.K. Singh, D.J. Pohlit. Journal of Adhesion Science and Technology 23: 5151530 (2009).

19. A. Turon, C.G. Dávila, P. P. Camanho and J. Costa. NASA/TM-2005-213547, March (2005).

20. K.N. Anyfantis and N.G. Tsouvalis. International Journal of Solids and Structures 49, 213 (2012).

21. V.K Goyal, E.R. Johnson and V.K. Goyal. Composite Structures 82, 434 (2008).

22. R.D.S.G. Campilho, M.F.S.F. de Moura and J.J.M.S. Domingues. Composites Science and Technology 65, 1948 (2005).

23. J.P.M. Gonçalves, M.F.S.F. de Moura, A.G. Magalhães and P.M.S.T. de Castro. Fatigue \& Fracture of Engineering Materials \& Structures 26, 479 (2003).

24. V. Tvergaard and J.W. Hutchinson. Journal of Mechanics and Physics of Solids 41, 1119 (1993). 25. V. Tvergaard and J.W. Hutchinson. Journal of Mechanics and Physics of Solids 44, 789 (1996).

26. D. Kubair and P. Geubelle. International Journal of Solids and Structures 40, 3853 (2003).

27. A. Needleman. Journal of Applied Mechanics: Transactions of the ASME 54, 525 (1987).

28. N.G. Tsouvalis and K.N. Anyfantis. Journal of Composite Materials 46, 27 (2012).

29. K.N. Anyfantis and N.G. Tsouvalis. Journal of Reinforced Plastics and Composites 30, 473 (2011).

30. M.J. van den Bosch, P.J.G. Schreurs and M.G.D. Geers. Engineering Fracture Mechanics 73, 1220 (2006).

31. Q.D. Yang, M.D. Thouless and S.W. Ward. Journal of the Mechanics and Physics of Solids 47, 1337 (1999).

32. Q.D. Yang and M.D. Thouless. International Journal of Fracture 110, 175 (2001). 
33. Q.D. Yang, M.D. Thouless and S.W. Ward. International Journal of Solids and Structures 38, 3251 (2001).

34. R.D.S.G. Campilho, M.F.S.F. de Moura and J.J.M.S. Domingues. International Journal of Solids and Structures 45, 1497 (2008).

35. R.D.S.G. Campilho, M.F.S.F. de Moura, A.M.G. Pinto, J.J.L. Morais and J.J.M.S. Domingues. Composites Part B 40, 149 (2009).

36. R.D.S.G. Campilho, M.F.S.F. de Moura, D.A.Ramantani, and Morais, J.J.L. and J.J.M.S. Domingues. International Journal of Adhesion and Adhesives 29, 678 (2009).

37. M.F.S.F. de Moura, R.D.S.G. Campilho and J.P.M. Gonçalves. International Journal of Solids and Structures 46, 1589 (2009).

38. K. Park, G.H. Paulino and J.R. Roesler. Journal of Mechanics and Physics of Solids 57, 891 (2009).

39. M. Alfano, F. Furgiuele, L. Leonardi, C. Maletta and G.H. Paulino. Key Eng Mater 348, 13 (2007).

40. M. Alfano, F. Furgiuele, L. Leonardi, C. Maletta and G.H. Paulino. 2009. International Journal of Fracture 157, 193 (2009).

41. M. J. van den Bosch , P. J. G. Schreurs , M. G. D. Geers. Comput Mech 42, 171 (2008).

42. G. Ji, Z. Ouyang, G. Li, S. Ibekwe and S.S.Pang. International Journal of Solids and Structures 47, 2445 (2010).

43. K. Leffler, K.S. Alfredsson and U. Stigh. International Journal of Solids and Structures 44, 530 (2007).

44. Information on http://www.intertronics.co.uk/data/ara2015.pdf (last visited in October 2011).

45. M.F.S.F. de Moura, R.D.S.G. Campilho, J.P.M. Gonçalves. Composites Science and Technology. 68, 2224 (2008). 


\section{$\underline{\text { List with figure legends }}$}

Figure 1: Proposed EPZ laws for the prediction of Mode I (a) and Mode II or III (b) loading and fracture.

Figure 2: Exponential form utilized for the traction strengthening part of the proposed EPZ law.

Figure 3: Analytical fitting with the proposed numerical EPZ law of a typical experimental T-S law in Mode I (a) and Mode II (b) loading and fracture.

Figure 4: Proposed mixed-mode EPZ model.

Figure 5: Geometrical configuration (dimensions in mm) of the SLJ (a) and the DSJ (b) specimens. Figure 6: Experimental setup in the testing machine of a SLJ (a) and a DSJ (b) specimen.

Figure 7: Finite element model of the SLJ - boundary conditions and detail of the overlap area.

Figure 8: Finite element model of the DSJ (1/4 of the full DSJ, with appropriate symmetry boundary conditions).

Figure 9: Von Mises stress distributions calculated within the linear elastic range of the adhesive material of the SLJ (a) and DSJ (b) model.

Figure 10: Experimental and numerical load-displacement curves for the SLJ (a) and DSJ (b) geometries.

Figure 11: Numerical results obtained from the sensitivity analysis of error parameter $e$ for the SLJ (a) and DSJ (b) case.

Figure 12: Dimensions and coordinate system of the overlap area of the SLJ (a) and the DSJ (b) configurations.

Figure 13: Peel stresses $\sigma_{\mathrm{z}}$ distributions over the adhesive area of the SLJ model for applied displacement u equal to $0.01 \mathrm{~mm}(\mathrm{a}), 0.1 \mathrm{~mm}$ (b) and $0.2 \mathrm{~mm}$ (c).

Figure 14: In-plane shear stresses $\tau_{\mathrm{xz}}$ distributions over the adhesive area of the SLJ model for applied displacement u equal to $0.01 \mathrm{~mm}$ (a), $0.1 \mathrm{~mm}$ (b) and $0.2 \mathrm{~mm}$ (c). 
Figure 15: Out-of-plane shear stresses $\tau_{\mathrm{yz}}$ distributions over the adhesive area of the SLJ model for applied displacement u equal to $0.2 \mathrm{~mm}$.

Figure 16: Distributions over the adhesive area domain of the separate terms of the quadratic stress criterion (see Equation 12 and Equation 29) that is satisfied at the maximum load capacity of the SLJ joint; contribution of $\sigma_{\mathrm{z}}$ (a), $\tau_{\mathrm{xz}}$ (b) and $\tau_{\mathrm{yz}}$ (c) stresses to the failure of the SLJ joint. Figure 17: Peel stresses $\sigma_{\mathrm{z}}$ distributions over the adhesive area of the DSJ model for applied displacement u equal to $0.01 \mathrm{~mm}(\mathrm{a}), 0.07 \mathrm{~mm}$ (b) and $0.11 \mathrm{~mm}(\mathrm{c})$. Figure 19: In-plane shear stresses $\tau_{\mathrm{xz}}$ distributions over the adhesive area of the DSJ model for applied displacement u equal to $0.01 \mathrm{~mm}$ (a), $0.07 \mathrm{~mm}$ (b) and $0.11 \mathrm{~mm}$ (c).

Figure 19: In-plane shear stresses $\tau_{\mathrm{yz}}$ distributions over the adhesive area of the DSJ model for applied displacement u equal to $0.11 \mathrm{~mm}$.

Figure 20: Distributions over the adhesive area domain of the separate terms of the quadratic stress criterion (see Equation 12 and Equation 29) that is satisfied at the maximum load capacity of the DSJ joint; contribution of $\sigma_{\mathrm{z}}(\mathrm{a}), \tau_{\mathrm{xz}}$ (b) and $\tau_{\mathrm{yz}}$ (c) stresses to the failure of the DSJ joint. 


\section{Tables}

Table 1: Physical parameters of the proposed pure mode EPZ laws.

\begin{tabular}{cccc}
\hline Mode $i$ & $k_{i}\left(\mathrm{~N} / \mathrm{mm}^{3}\right)$ & $\sigma_{\mathrm{c}, i}(\mathrm{MPa})$ & $J_{\text {ic }}(\mathrm{N} / \mathrm{mm})$ \\
\hline I & 3700 & 30.0 & 4.0 \\
II & 1423 & 18.5 & 4.7 \\
III & 1423 & 18.5 & 4.7 \\
\hline
\end{tabular}


Table 2: Experimentally measured and numerically predicted failure load $P_{\max }$ and corresponding displacement $u_{\max }$ for the SLJ case.

\begin{tabular}{ccccccccc}
\hline & Exp. 1 & Exp. 2 & Exp. 3 & Exp. & FEA & Diff. \% & FEA & Diff. \% \\
& & & & Average & proposed & & trapezoidal & \\
\hline$P_{\max }(\mathrm{kN})$ & 13.20 & 12.90 & 14.30 & 13.47 & 13.07 & 2.96 & 12.90 & 4.24 \\
$u_{\max }(\mathrm{mm})$ & 0.240 & 0.237 & 0.247 & 0.241 & 0.199 & 17.40 & 0.160 & 33.6 \\
\hline
\end{tabular}


Table 3: Experimentally measured and numerically predicted failure load $P_{\max }$ and corresponding displacement $u_{\max }$ for the DSJ case.

\begin{tabular}{|c|c|c|c|c|c|c|c|c|}
\hline & Exp. 1 & Exp. 2 & Exp. 3 & $\begin{array}{c}\text { Exp. } \\
\text { Average }\end{array}$ & $\begin{array}{c}\text { FEA } \\
\text { proposed }\end{array}$ & Diff. \% & $\begin{array}{c}\text { FEA } \\
\text { trapezoidal }\end{array}$ & Diff. \% \\
\hline$P_{\max }(\mathrm{kN})$ & 42.98 & 43.66 & 41.00 & 42.55 & 43.20 & 1.52 & 43.40 & 1.99 \\
\hline$u_{\max }(\mathrm{mm})$ & 0.111 & 0.105 & 0.099 & 0.105 & 0.139 & 32.3 & 0.149 & 41.9 \\
\hline
\end{tabular}




\section{$\underline{\text { Figures }}$}



(a)

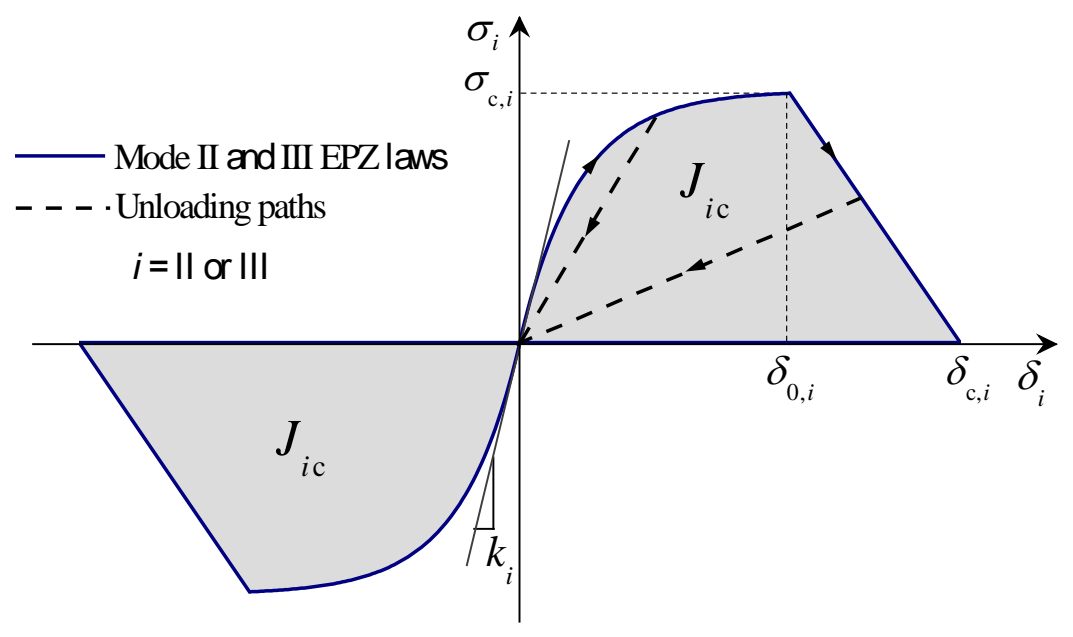

(b)

Figure 1: Proposed EPZ laws for the prediction of Mode I (a) and Mode II or III (b) loading and fracture. 




Figure 2: Exponential form utilized for the traction strengthening part of the proposed EPZ law. 




(a)

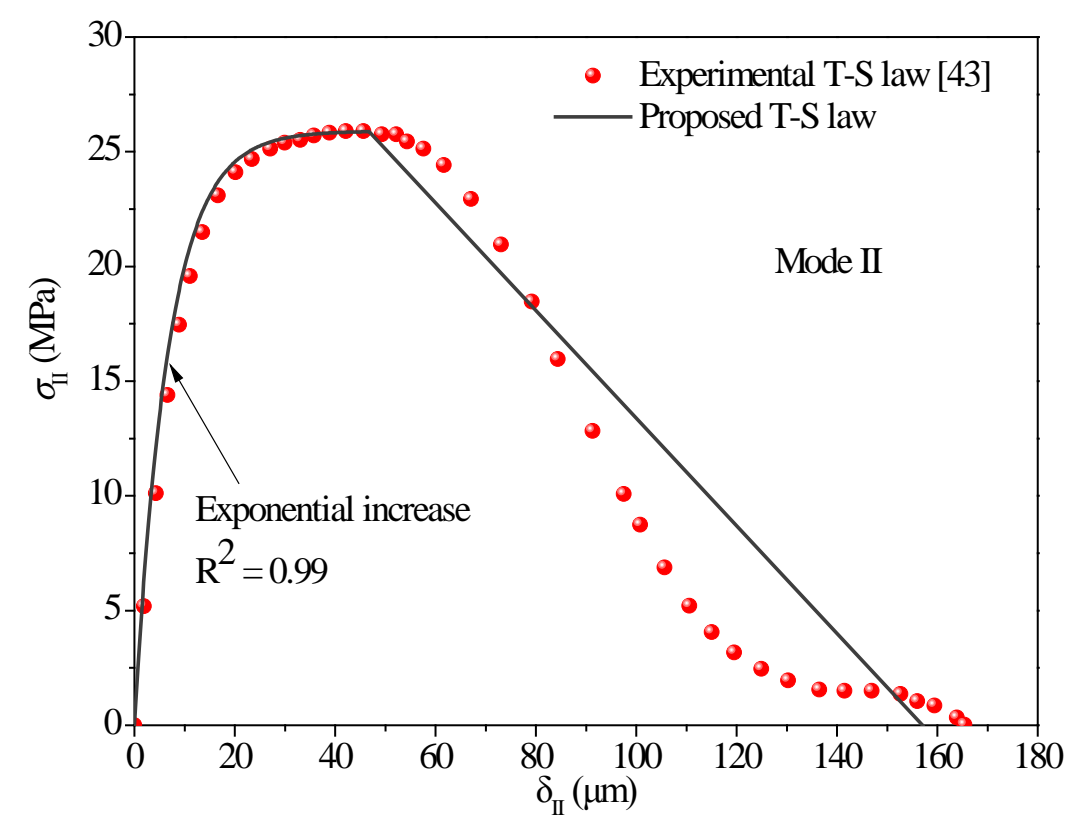

(b)

Figure 3: Analytical fitting with the proposed numerical EPZ law of a typical experimental T-S law in Mode I (a) and Mode II (b) loading and fracture. 


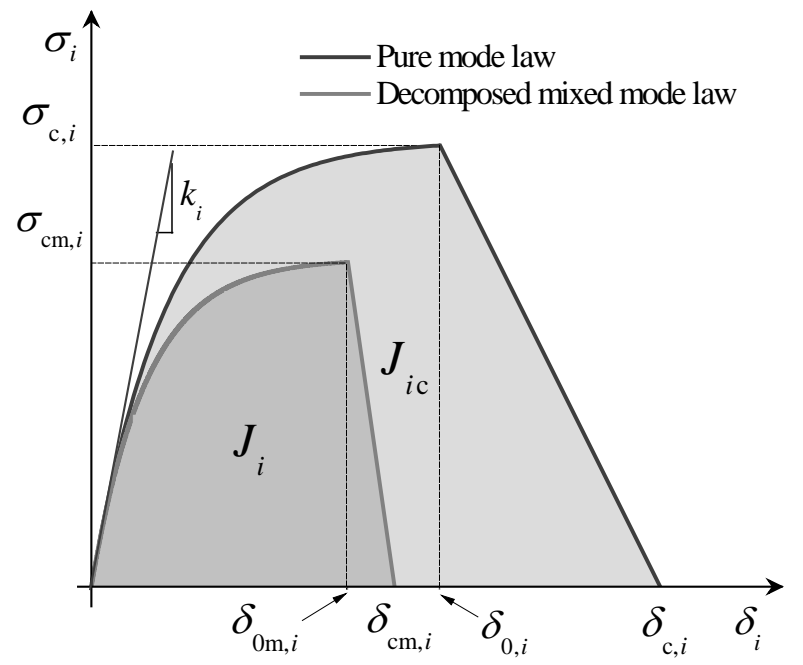

Figure 4: Proposed mixed-mode EPZ model. 


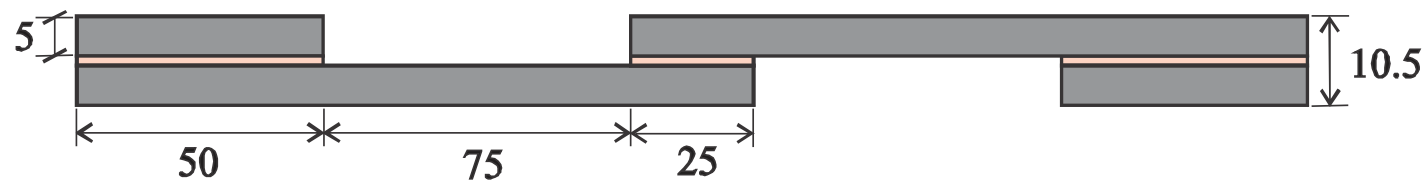

(a)



(b)

Figure 5: Geometrical configuration (dimensions in $\mathrm{mm}$ ) of the SLJ (a) and the DSJ (b) specimens.

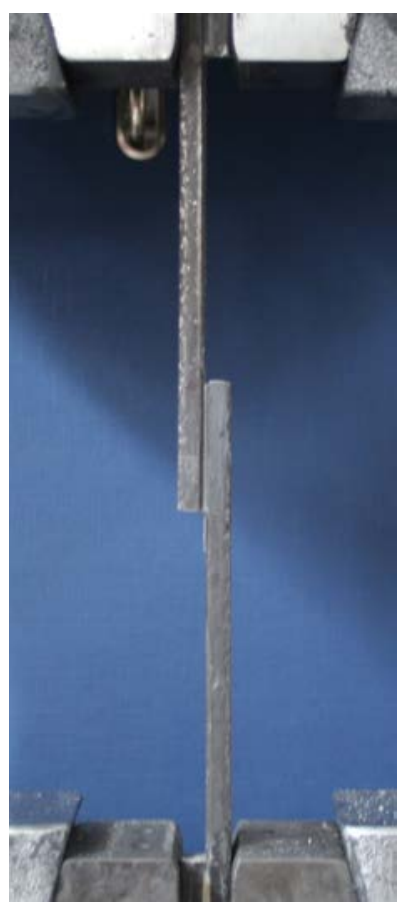

(a)

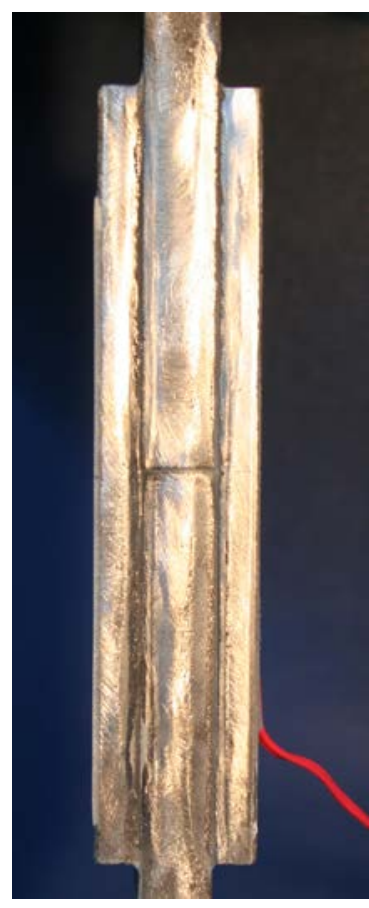

(b)

Figure 6: Experimental setup in the testing machine of a SLJ (a) and a DSJ (b) specimen. 


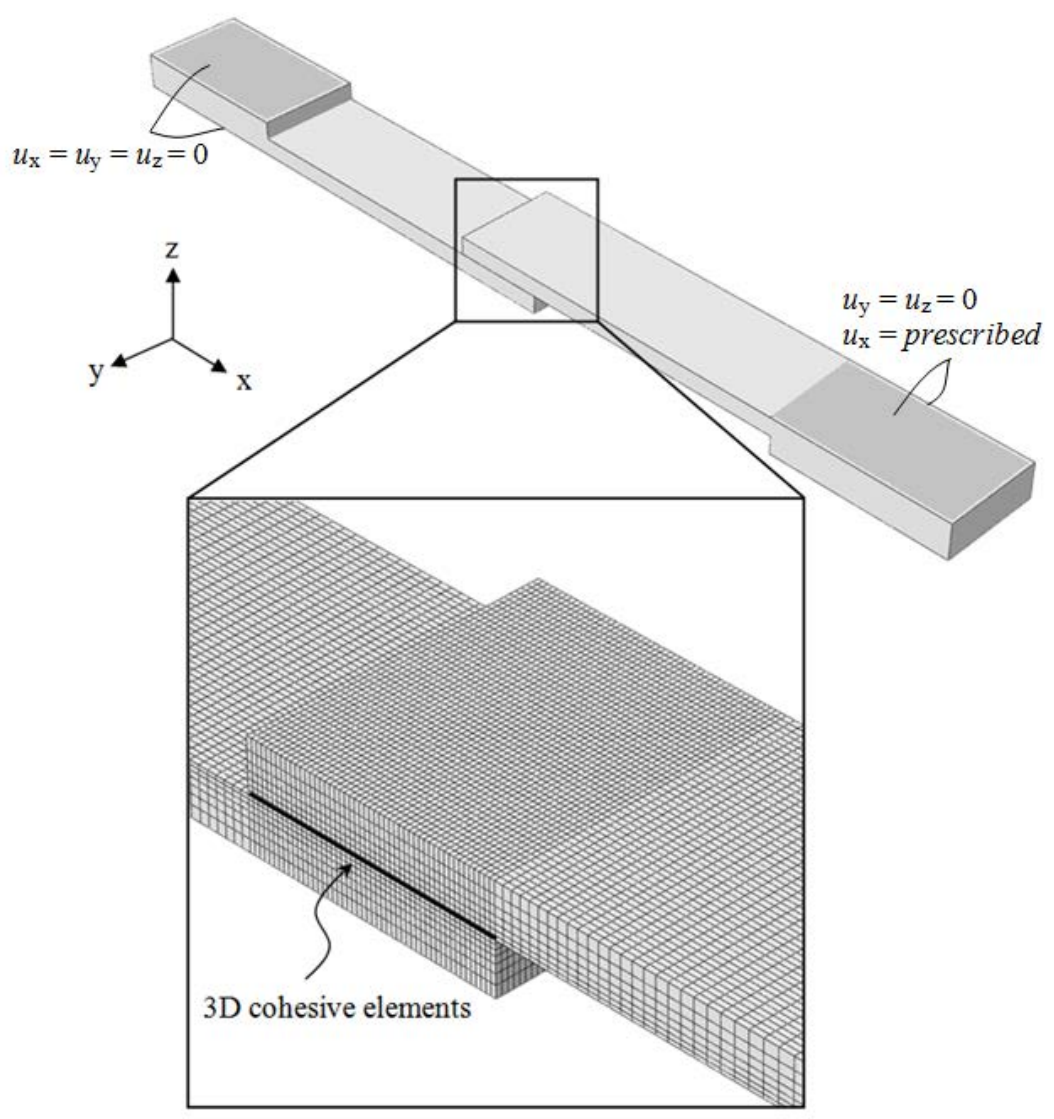

Figure 7: Finite element model of the SLJ - boundary conditions and detail of the overlap area. 


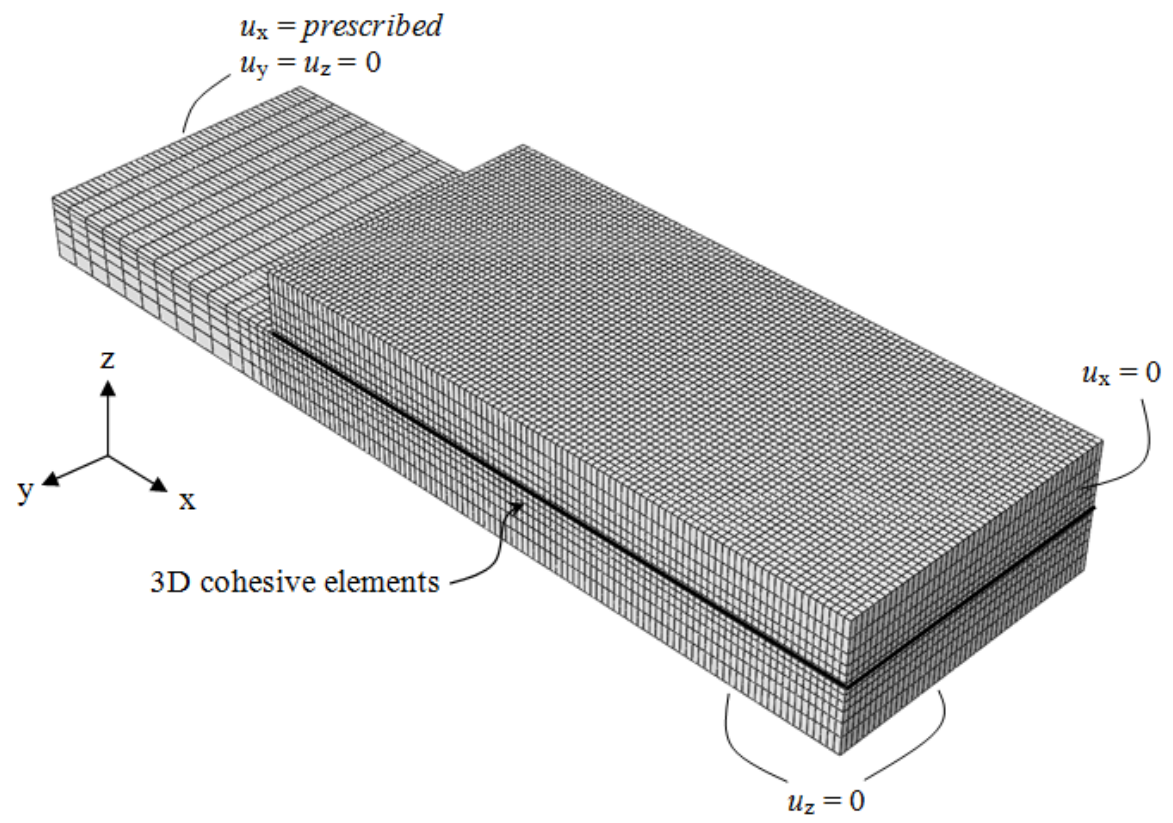

Figure 8: Finite element model of the DSJ (1/4 of the full DSJ, with appropriate symmetry boundary conditions). 


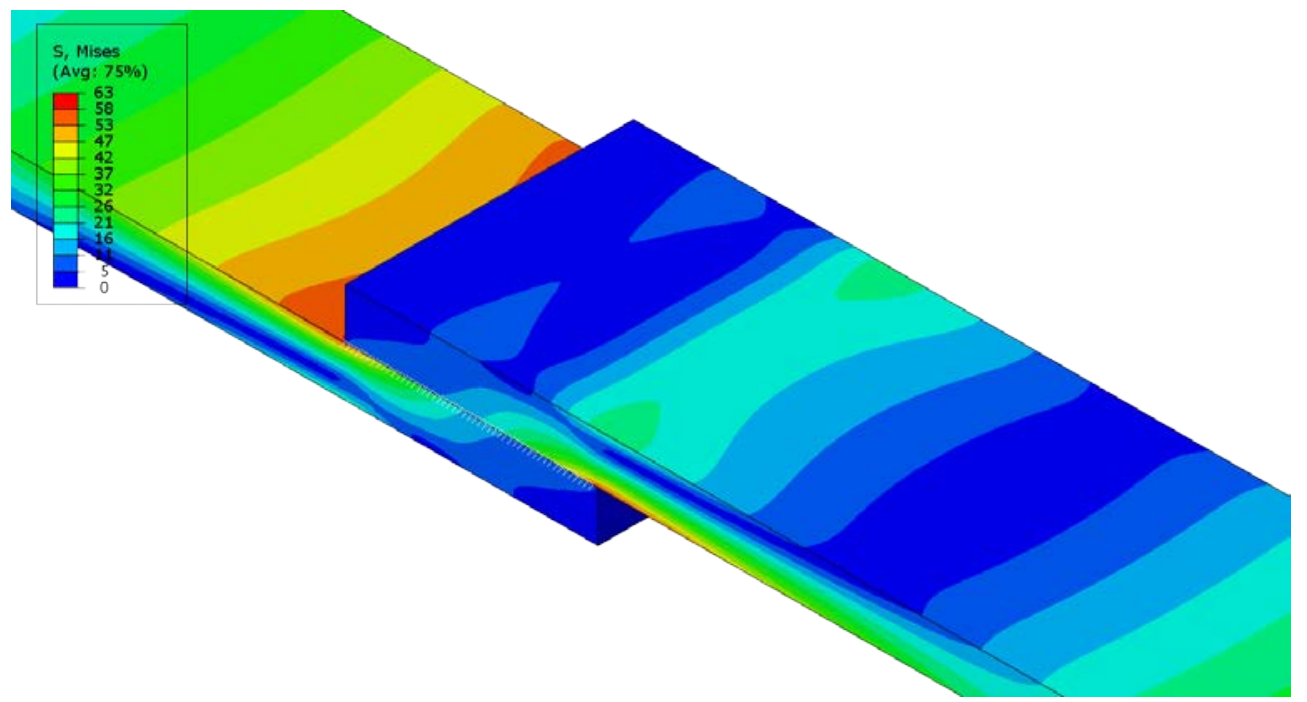

(a)

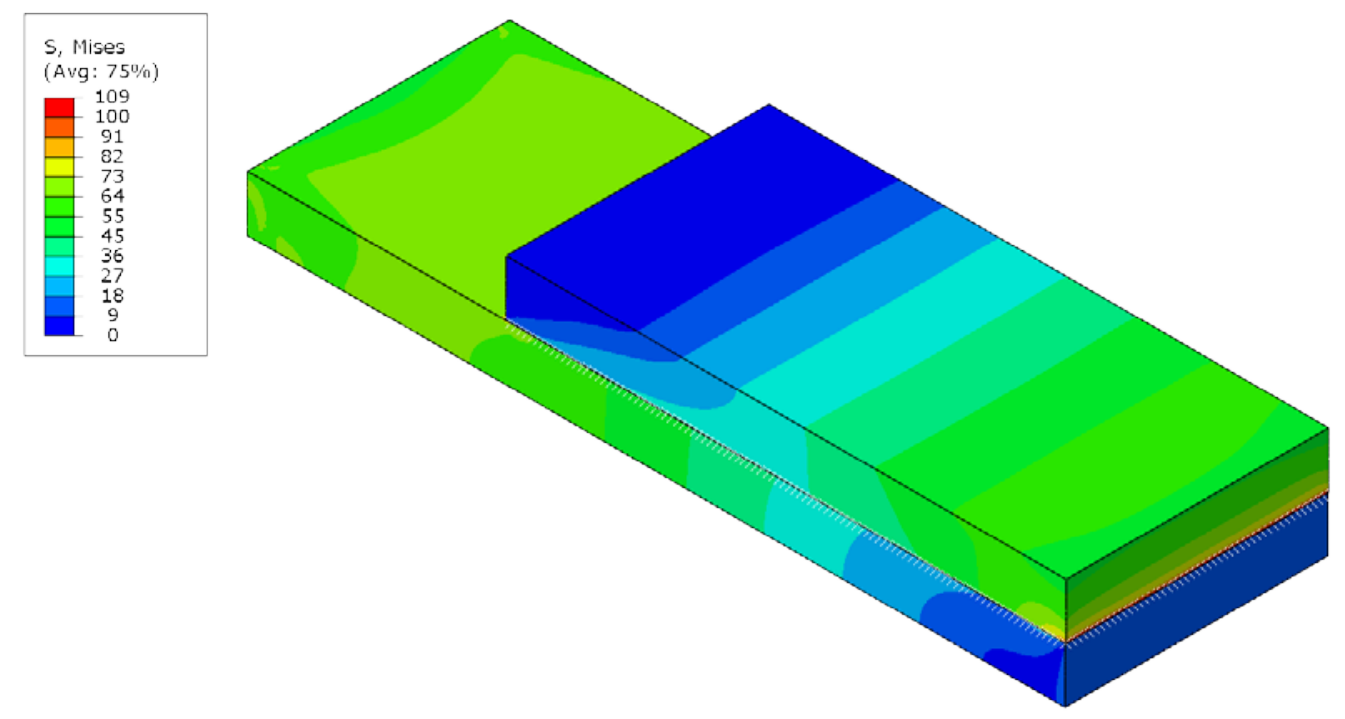

(b)

Figure 9: Von Mises stress distributions calculated within the linear elastic range of the adhesive material of the SLJ (a) and DSJ (b) model. 


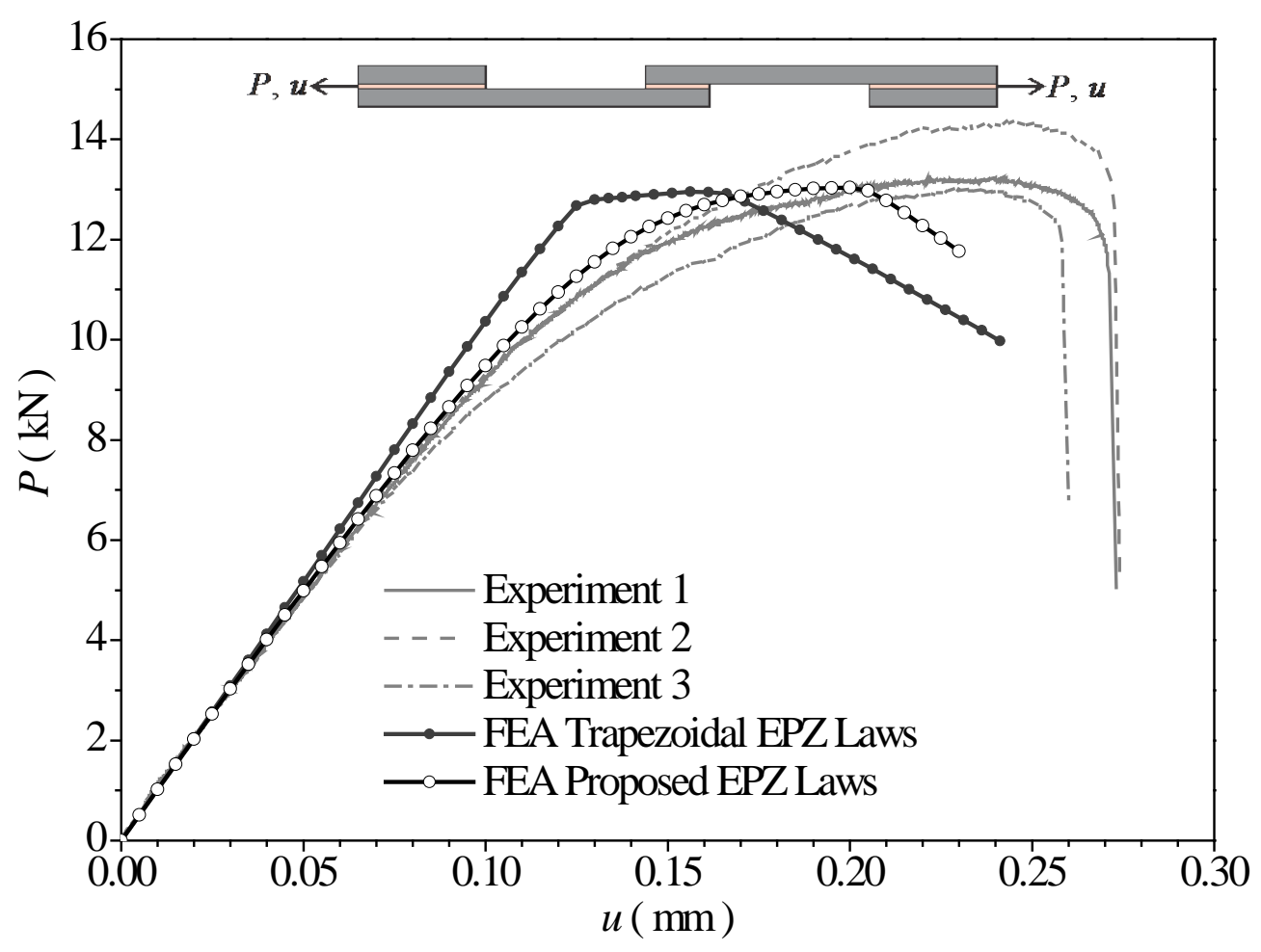

(a)

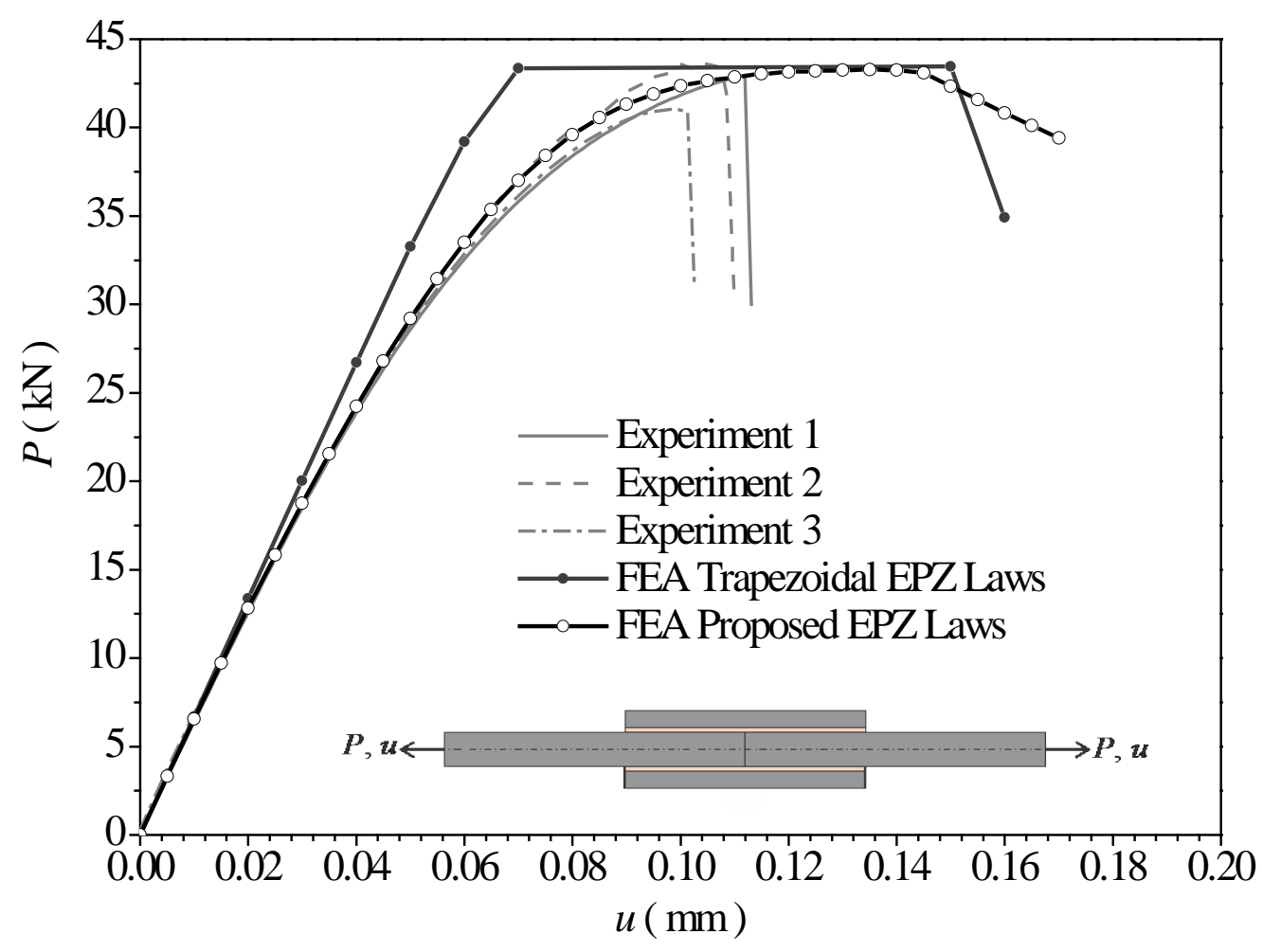

(b)

Figure 10: Experimental and numerical load-displacement curves for the SLJ (a) and DSJ (b) geometries. 


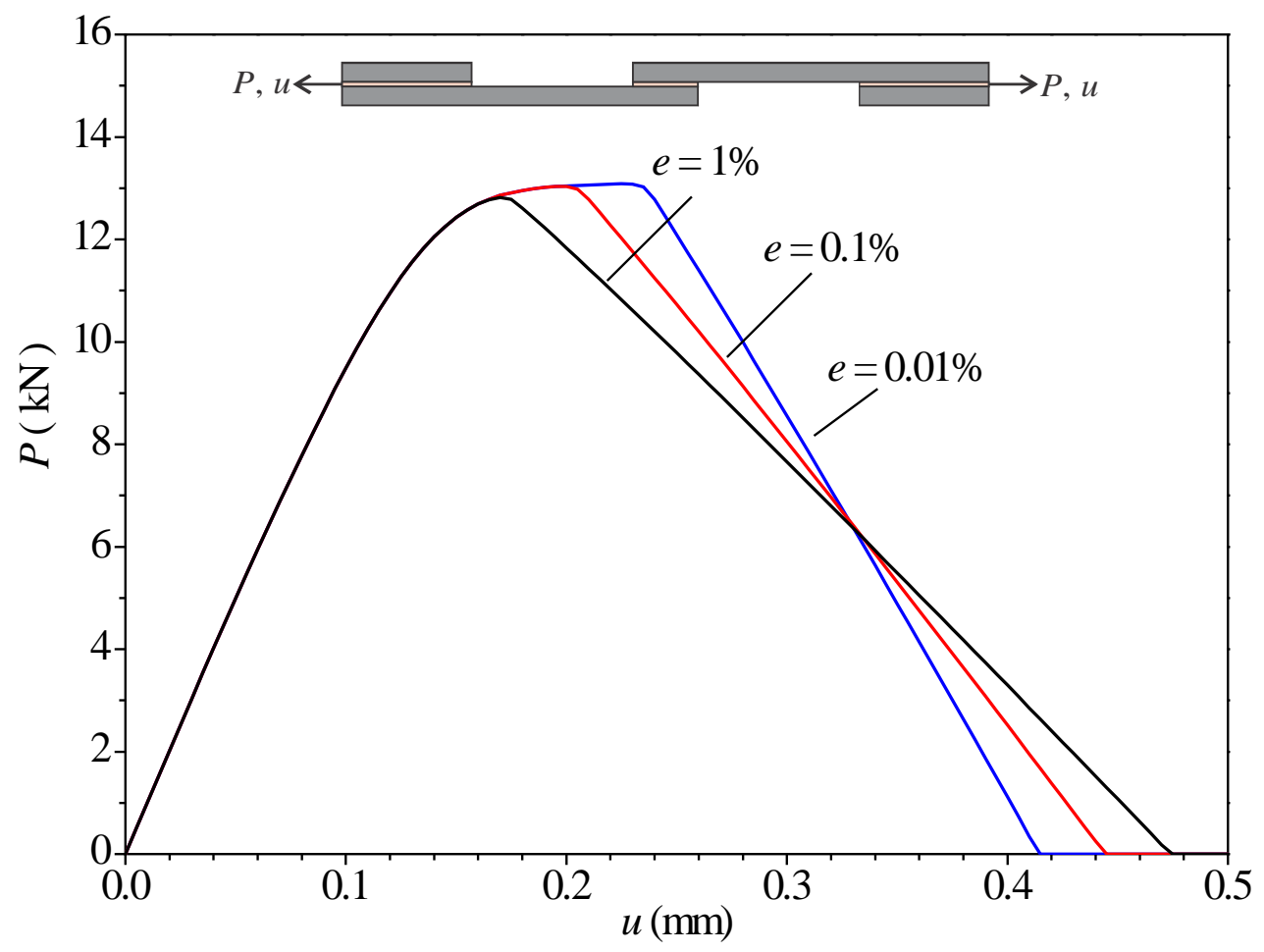

(a)

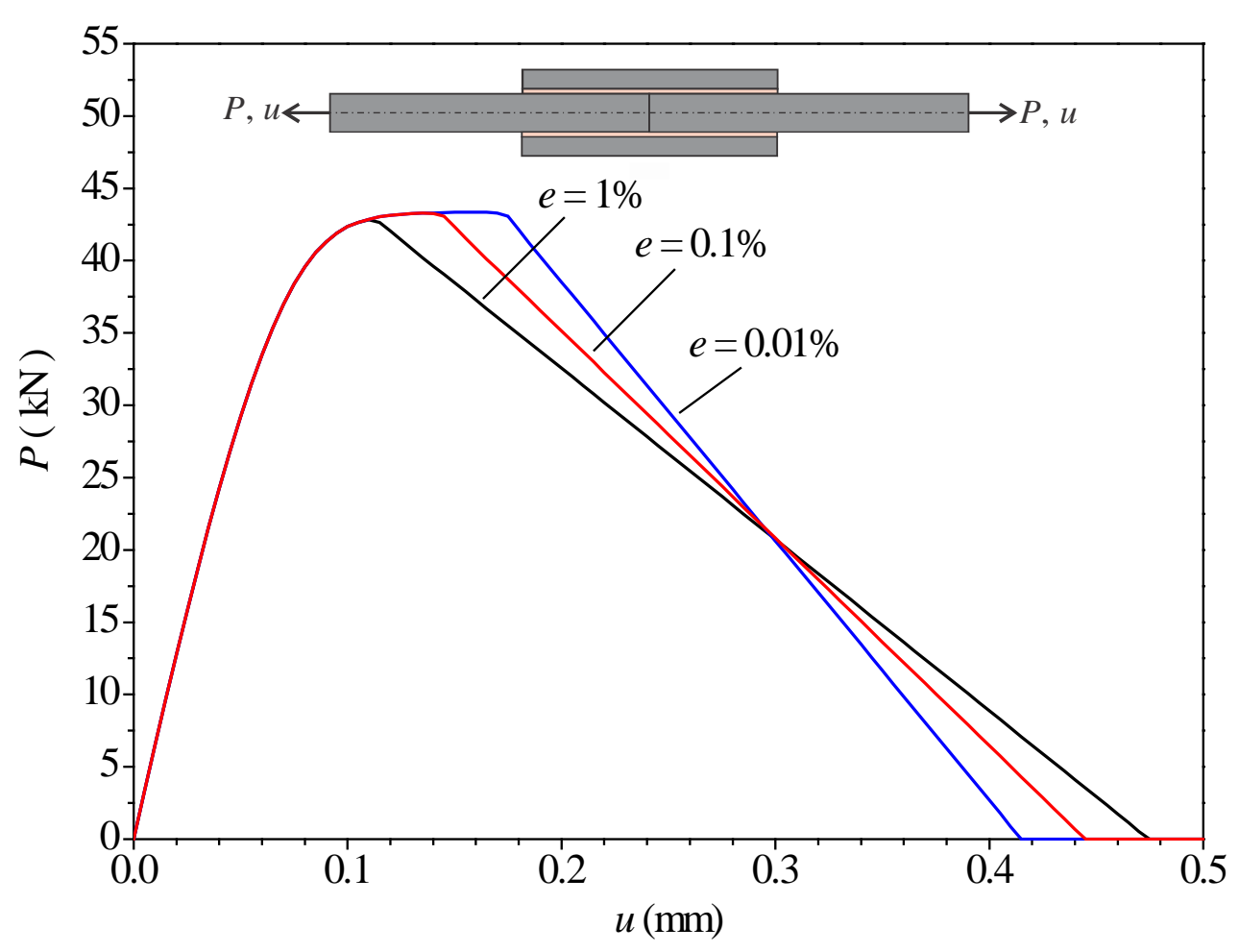

(b)

Figure 11: Numerical results obtained from the sensitivity analysis of error parameter $e$ for the SLJ (a) and DSJ (b) case. 




(a)

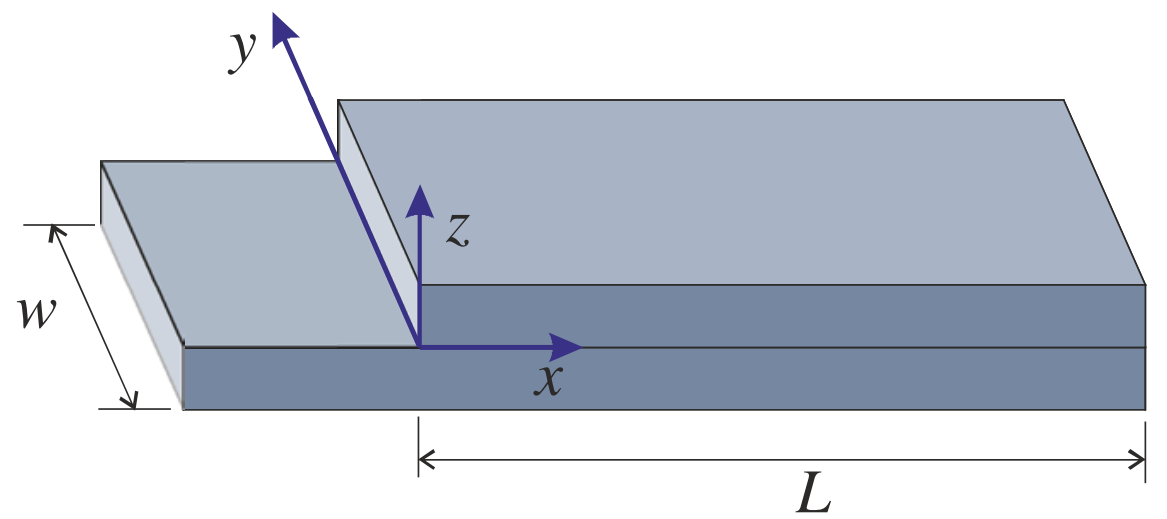

(b)

Figure 12: Dimensions and coordinate system of the overlap area of the SLJ (a) and the DSJ (b) configurations. 


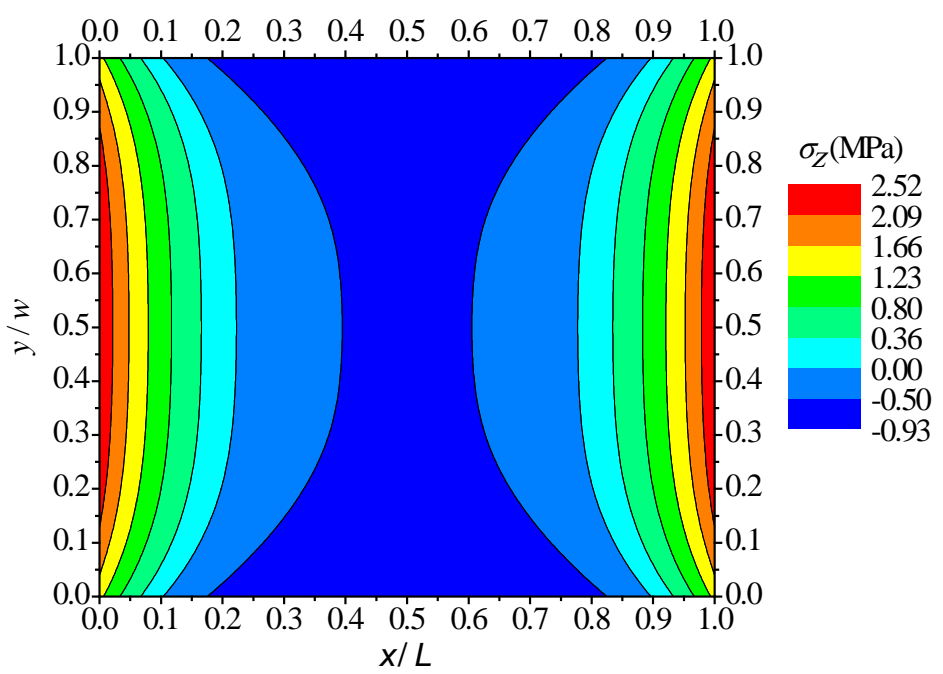

(a)

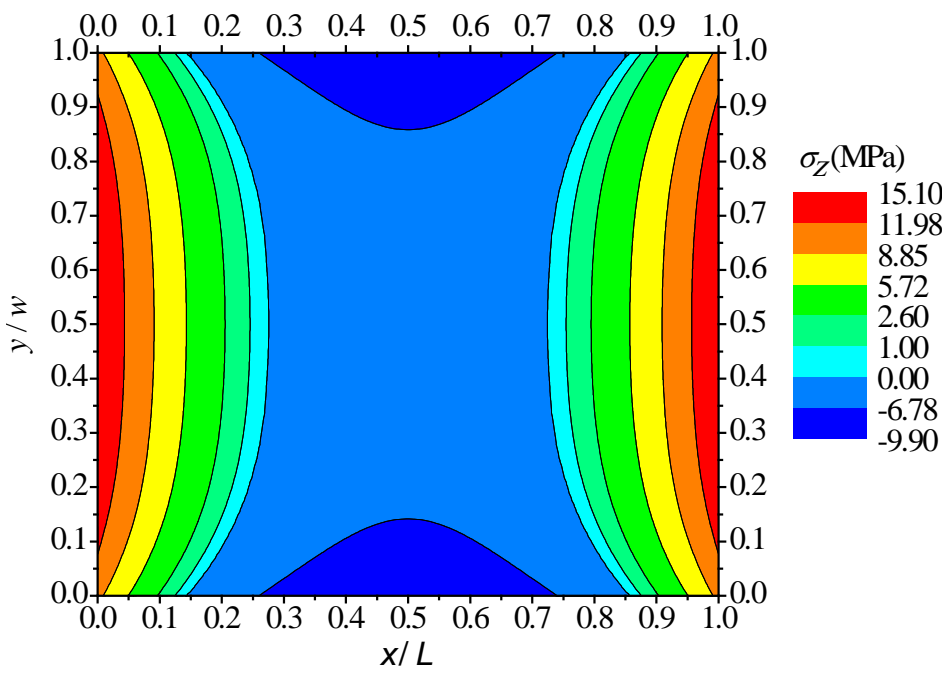

(b)



(c)

Figure 13: Peel stresses $\sigma_{\mathrm{z}}$ distributions over the adhesive area of the SLJ model for applied displacement $u$ equal to $0.01 \mathrm{~mm}$ (a), $0.1 \mathrm{~mm}$ (b) and $0.2 \mathrm{~mm}$ (c). 




(a)



(b)

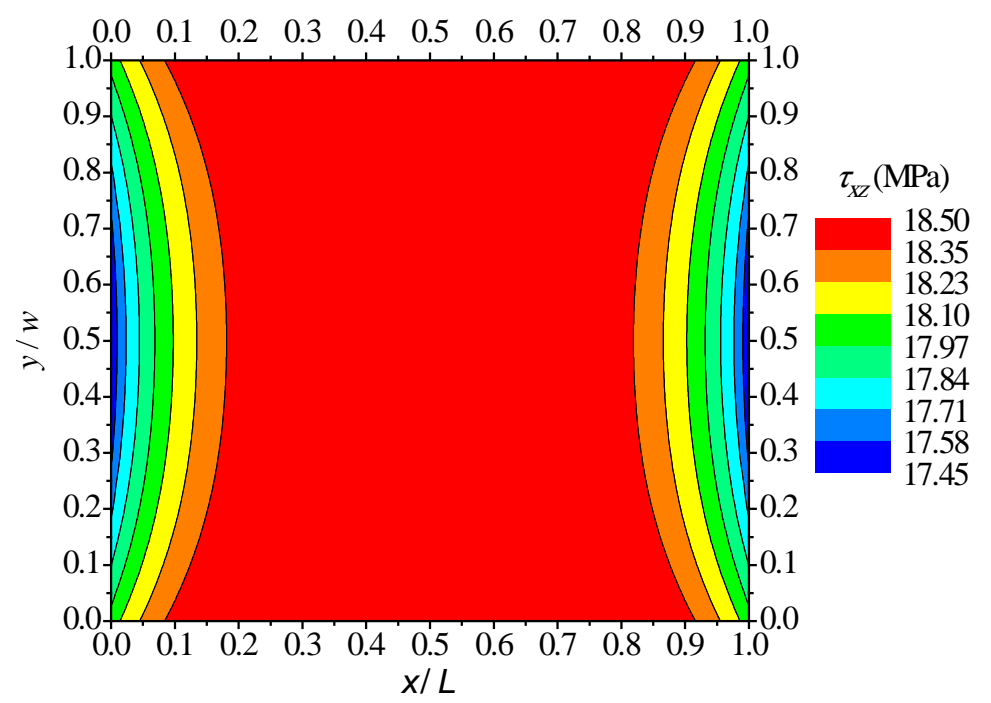

(c)

Figure 14: In-plane shear stresses $\tau_{x z}$ distributions over the adhesive area of the SLJ model for applied displacement $u$ equal to $0.01 \mathrm{~mm}$ (a), $0.1 \mathrm{~mm}$ (b) and $0.2 \mathrm{~mm}$ (c). 


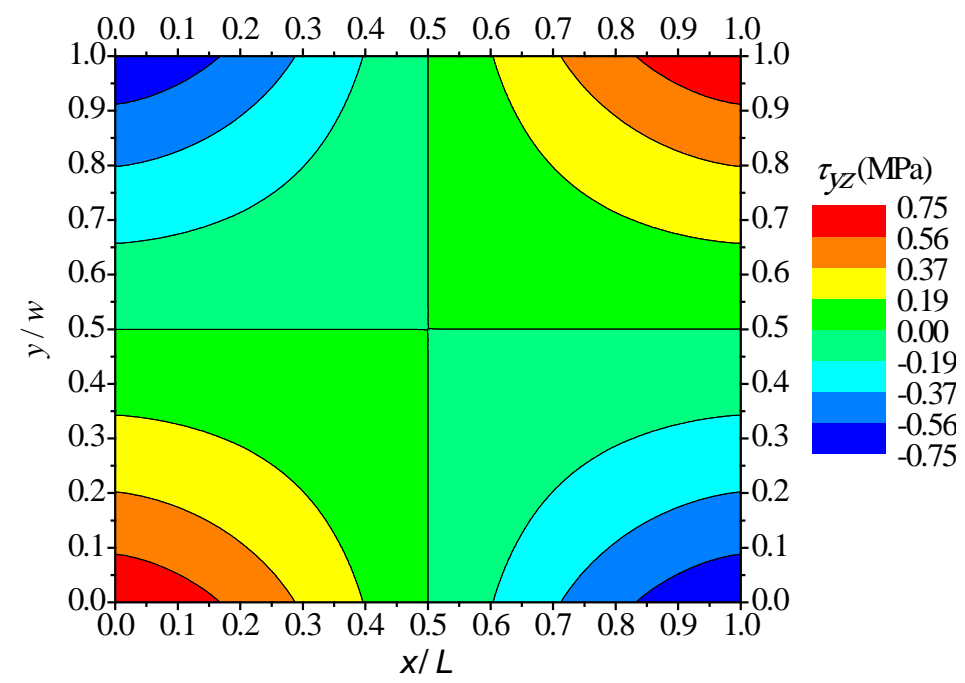

Figure 15: Out-of-plane shear stresses $\tau_{y z}$ distributions over the adhesive area of the SLJ model for applied displacement $u$ equal to $0.2 \mathrm{~mm}$. 


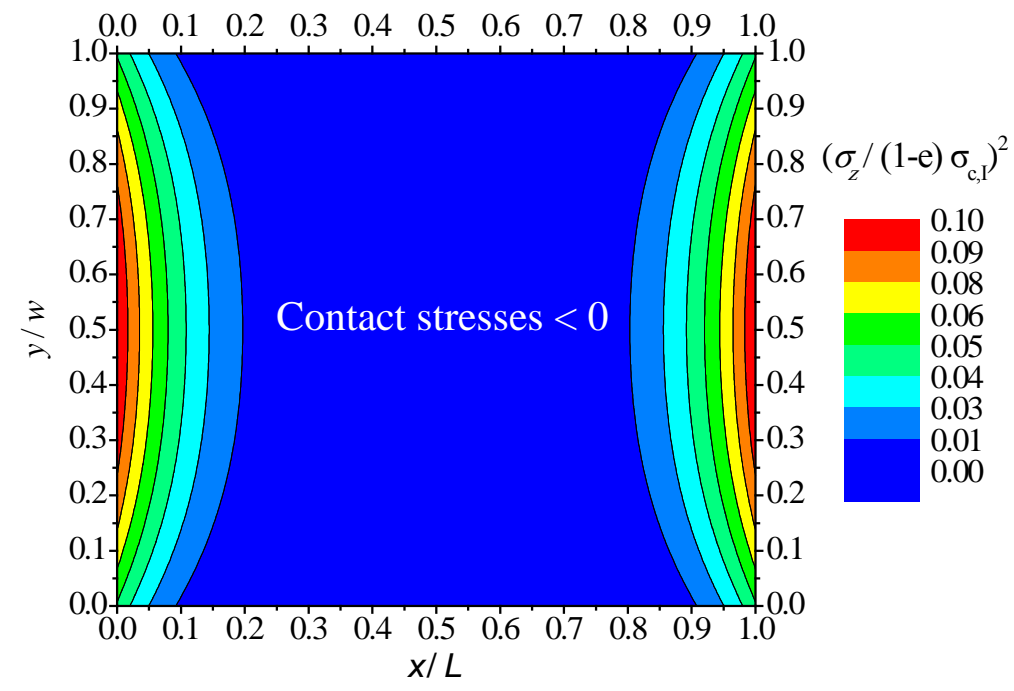

(a)

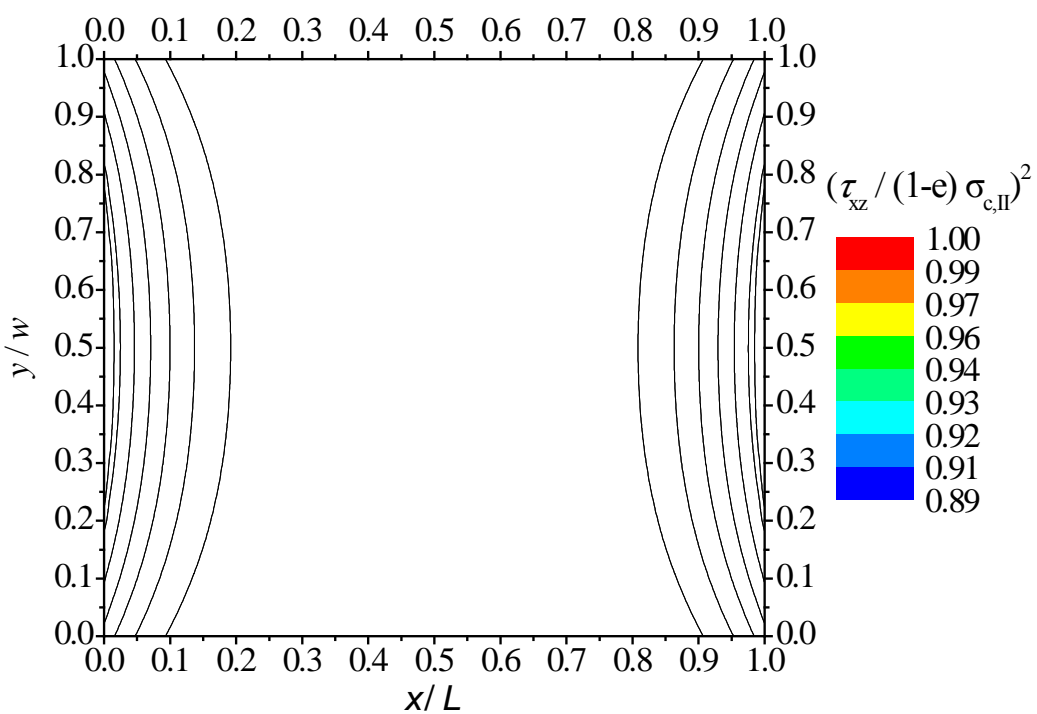

(b)

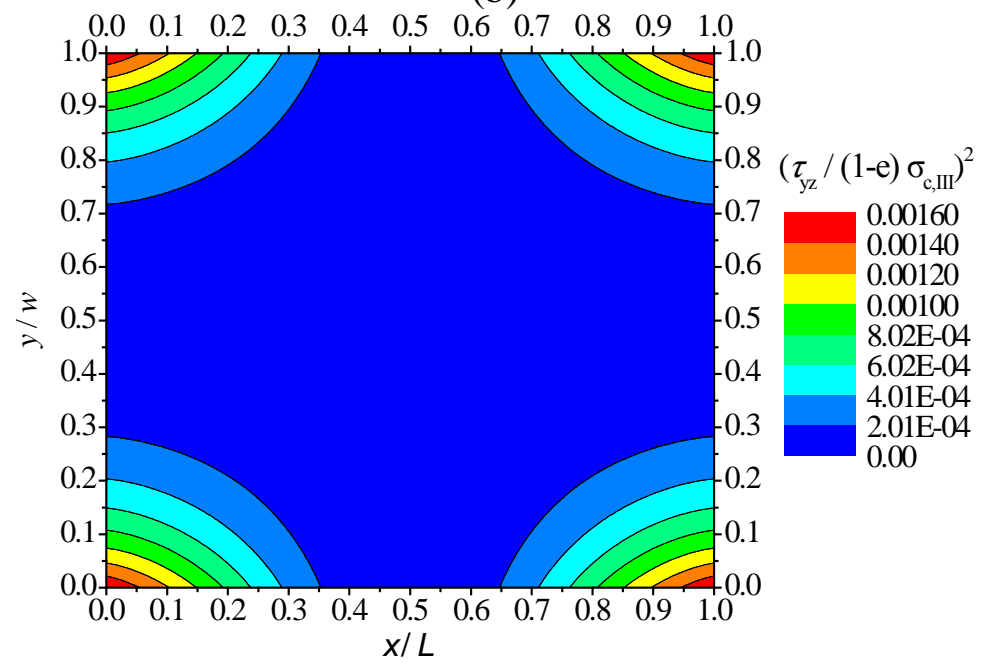

(c)

Figure 16: Distributions over the adhesive area domain of the separate terms of the quadratic stress criterion (see Equation 12 and Equation 29) that is satisfied at the maximum load capacity of the SLJ joint; contribution of $\sigma_{\mathrm{z}}$ (a), $\tau_{\mathrm{xz}}$ (b) and $\tau_{\mathrm{yz}}$ (c) stresses to the failure of the SLJ joint. 



(a)

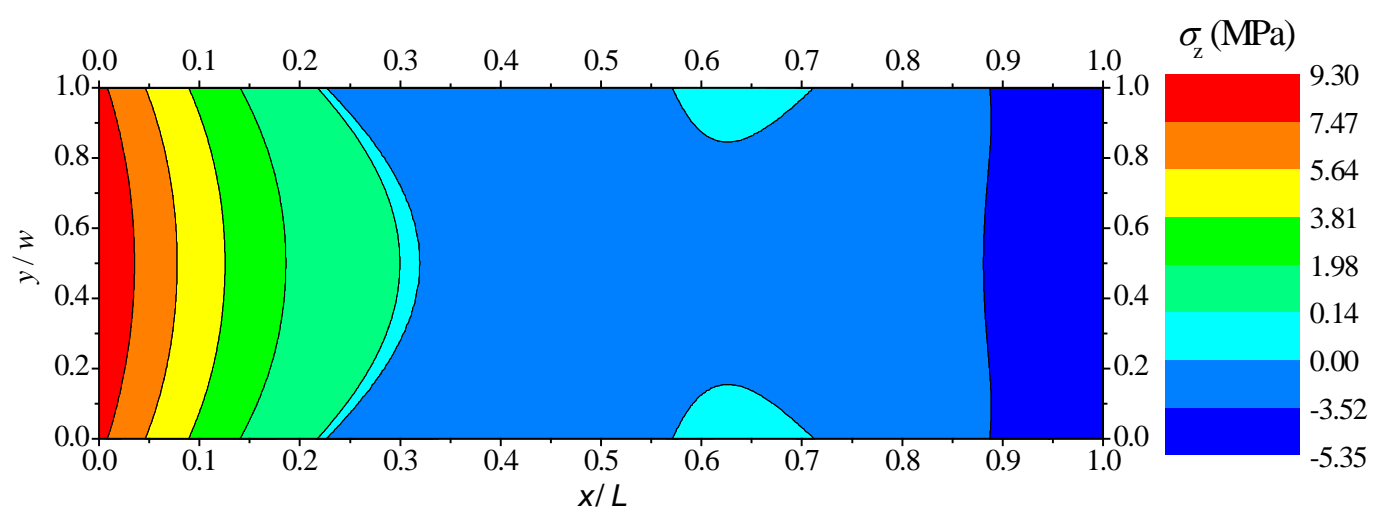

(b)



(c)

Figure 17: Peel stresses $\sigma_{\mathrm{z}}$ distributions over the adhesive area of the DSJ model for applied displacement $u$ equal to $0.01 \mathrm{~mm}$ (a), $0.07 \mathrm{~mm}$ (b) and $0.11 \mathrm{~mm}$ (c). 




(a)
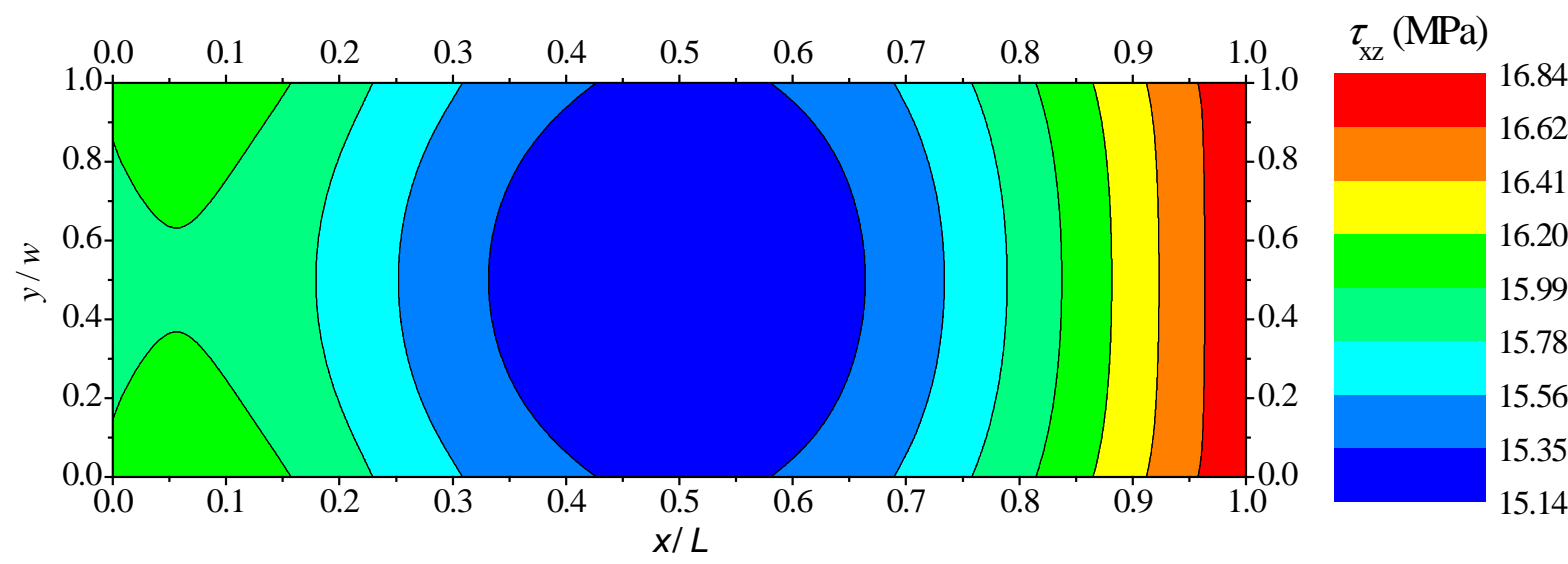

(b)

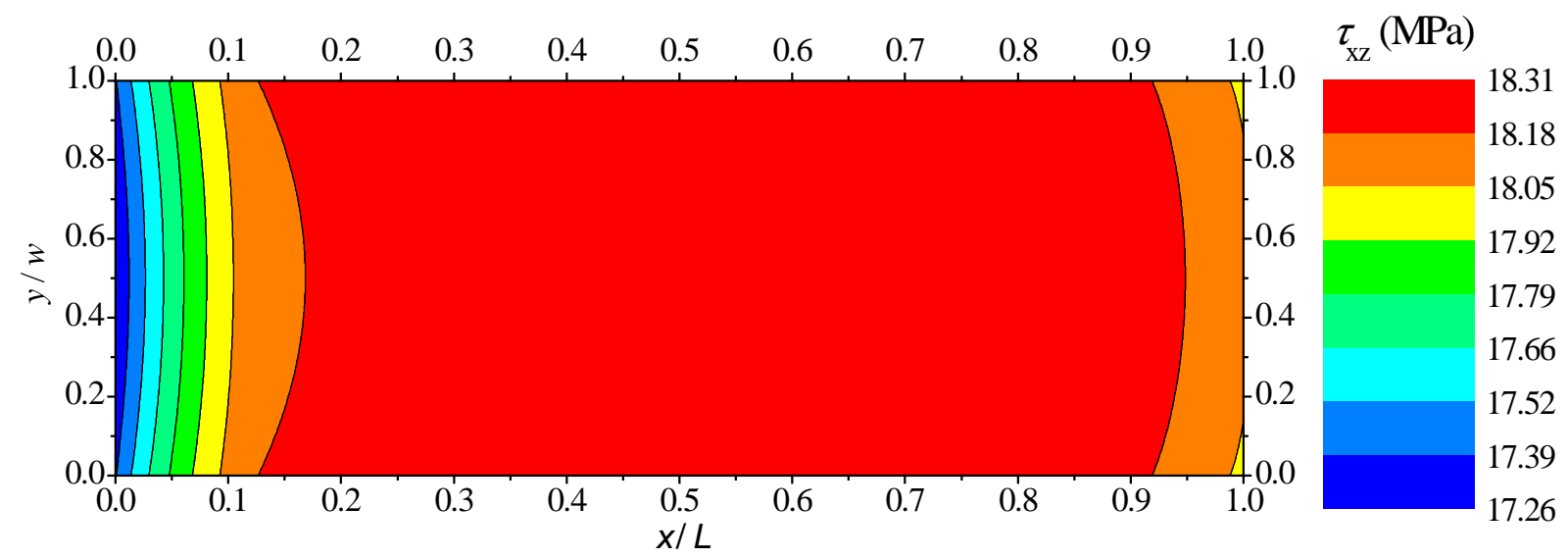

(c)

Figure 18: In-plane shear stresses $\tau_{x z}$ distributions over the adhesive area of the DSJ model for applied displacement $u$ equal to $0.01 \mathrm{~mm}$ (a), $0.07 \mathrm{~mm}$ (b) and $0.11 \mathrm{~mm}$ (c). 


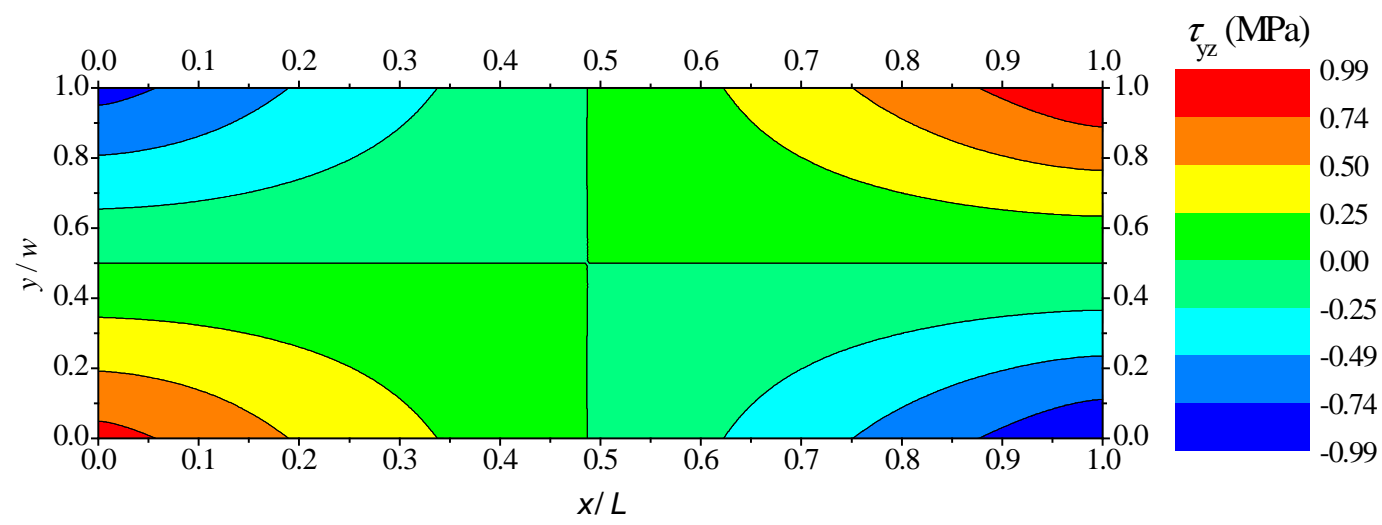

Figure 19: In-plane shear stresses $\tau_{y z}$ distributions over the adhesive area of the DSJ model for applied displacement $u$ equal to $0.11 \mathrm{~mm}$. 



(a)
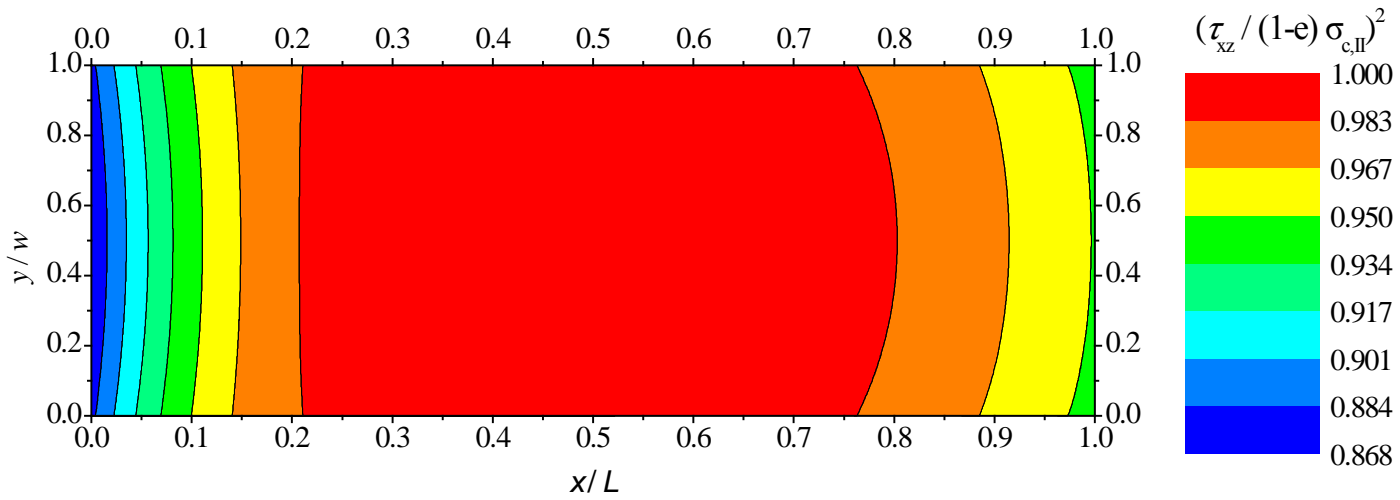

(b)
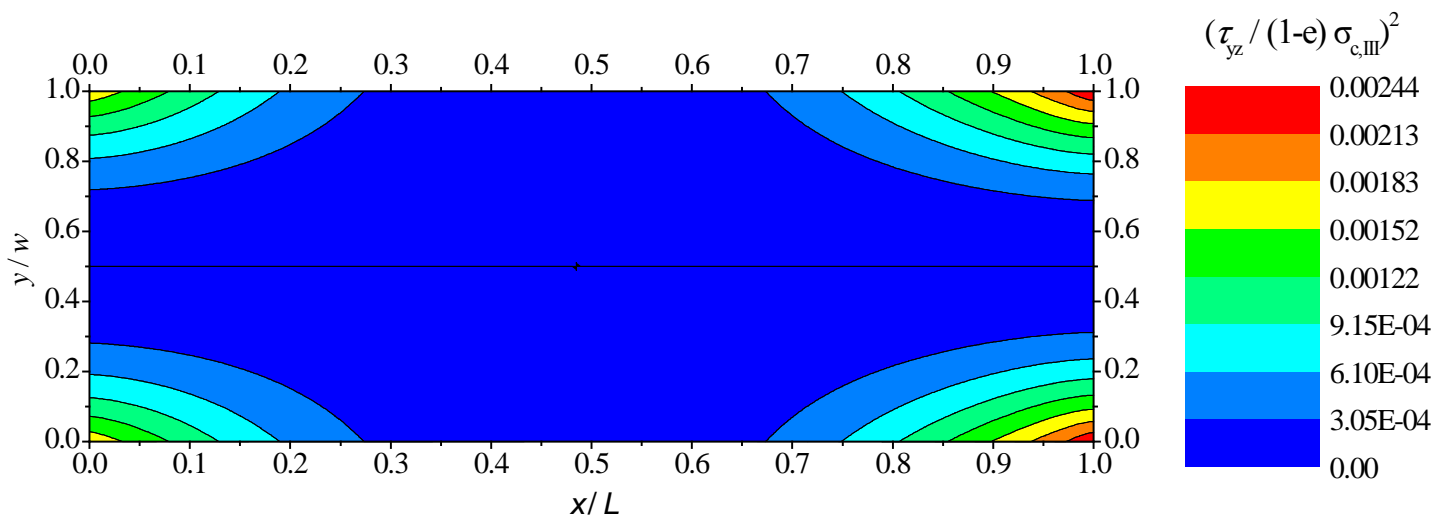

(c)

Figure 20: Distributions over the adhesive area domain of the separate terms of the quadratic stress criterion (see Equation 12 and Equation 29) that is satisfied at the maximum load capacity of the DSJ joint; contribution of $\sigma_{\mathrm{z}}(\mathrm{a}), \tau_{\mathrm{xz}}$ (b) and $\tau_{\mathrm{yz}}$ (c) stresses to the failure of the DSJ joint. 